Portland State University

PDXScholar

$5-5-2020$

\title{
An Examination of Daily Family-Supportive Supervisor Behaviors, Perceived Supervisor Responsiveness and Job Satisfaction
}

Luke Daniel Mahoney

Portland State University

Follow this and additional works at: https://pdxscholar.library.pdx.edu/open_access_etds

Part of the Psychology Commons

Let us know how access to this document benefits you.

\section{Recommended Citation}

Mahoney, Luke Daniel, "An Examination of Daily Family-Supportive Supervisor Behaviors, Perceived Supervisor Responsiveness and Job Satisfaction" (2020). Dissertations and Theses. Paper 5438. https://doi.org/10.15760/etd.7311

This Thesis is brought to you for free and open access. It has been accepted for inclusion in Dissertations and Theses by an authorized administrator of PDXScholar. Please contact us if we can make this document more accessible: pdxscholar@pdx.edu. 
An Examination of Daily Family-Supportive Supervisor Behaviors, Perceived Supervisor Responsiveness and Job Satisfaction

by

Luke Daniel Mahoney

A thesis submitted in partial fulfillment of the requirements for the degree of

Master of Science

in

Psychology

Thesis Committee:

Leslie B. Hammer, Chair

Todd E. Bodner

Cynthia D. Mohr

Portland State University

2020 
C2020 Luke Daniel Mahoney 


\begin{abstract}
Balancing both work and non-work life is increasingly recognized as a challenge for employees, and supervisors are in a position to support employees in their efforts to do so. Supervisors who exhibit family-supportive behaviors in support of employees who juggle work and family roles show benefits for employees in terms of well-being and job outcomes. The purpose of this study was to take a more fine-grained look at familysupportive supervisor behaviors (FSSB) using daily surveys in order to advance understanding of how family-supportive behaviors work within-person. Another aim of the study was to examine perceived supervisor responsiveness (PSR) for the first time, to validate it against FSSB and job satisfaction, and to position it as a mediator of the positive effects of FSSB on job satisfaction. Participants consisted of 155 veterans from the broader Study for Employment Retention of Veterans who also completed a dailysurvey study. A total of 1054 work days were considered in this study, an average of 6.8 days per person with a median of 6. A multi-level factor analysis showed that FSSB and PSR were distinct constructs at both the day-level (level-0) and person-level (level-1). FSSB, PSR, and job satisfaction showed within-person variation of $33 \%, 23 \%$, and $35 \%$ respectively. A series of mixed-effects models were employed to test within-person relationships between the constructs of interest. As hypothesized, both FSSB and PSR showed significant within-person relationships with job satisfaction when examined as single predictors, $\gamma_{10}=.160, p<.001$ and $\gamma_{10}=.231, p<.001$, respectively. Examined simultaneously, FSSB was not a significant predictor of job satisfaction while PSR remained a significant predictor of job satisfaction. Analysis of mediation showed that PSR significantly mediated the relationship between FSSB and job satisfaction, showing
\end{abstract}


support for another of this study's hypotheses. This study constitutes a step forward in understanding FSSB. Altogether, this study shows that perceptions of FSSB may be influenced by daily processes and these shifts influence feelings about the quality of the relationship one has with their supervisor as well as job satisfaction. The merits of this study and implications for future research on FSSB and PSR are discussed. 
Table of Contents

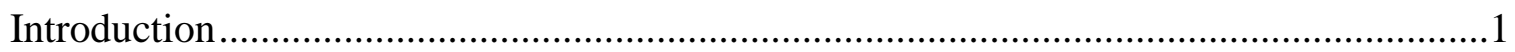

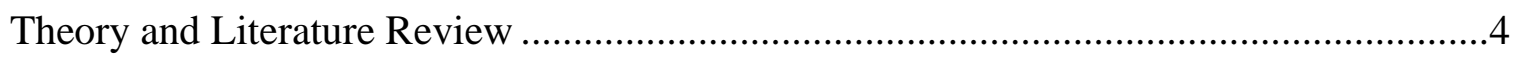

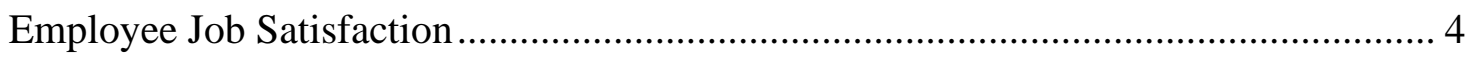

Family-Supportive Supervisor Behaviors ........................................................... 9

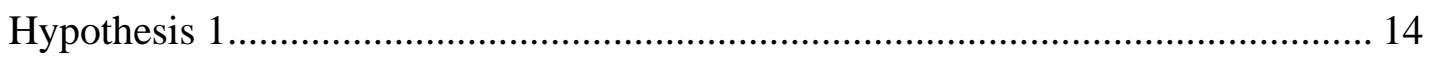

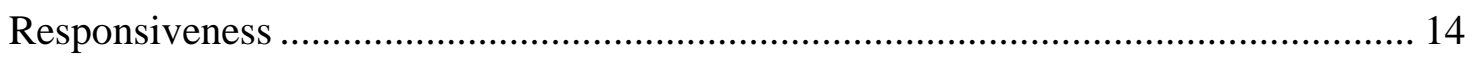

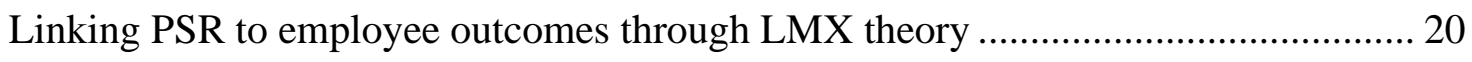

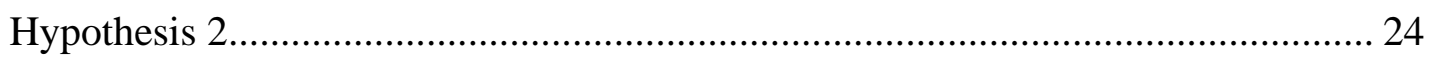

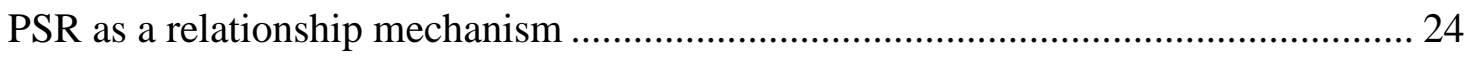

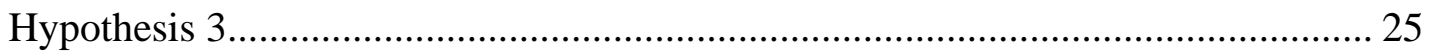

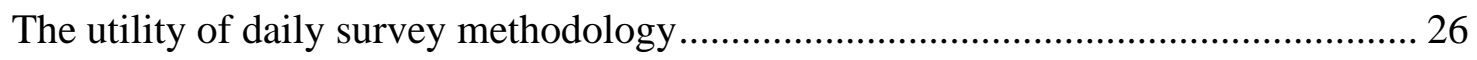

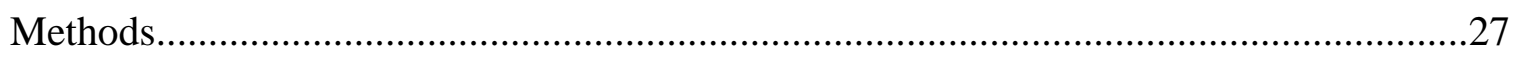

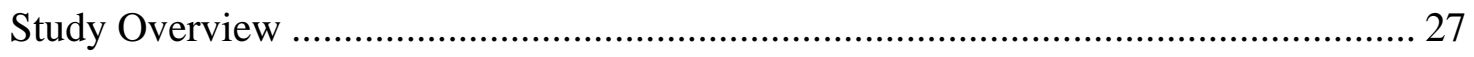

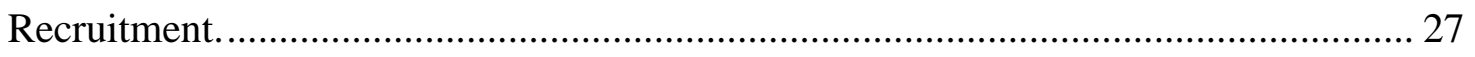

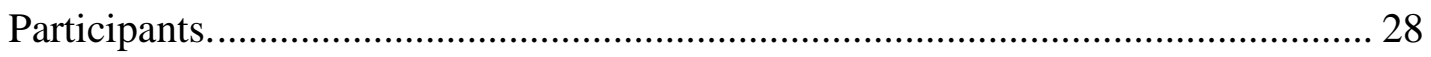

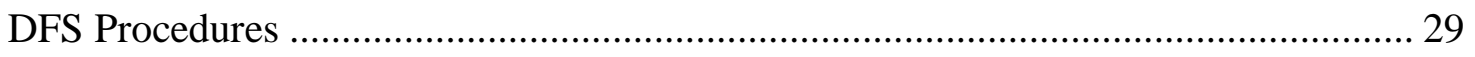

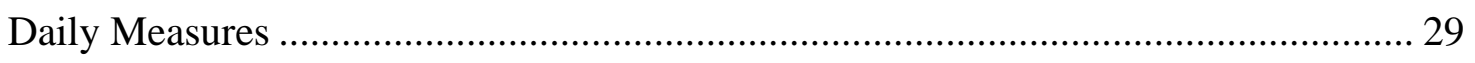

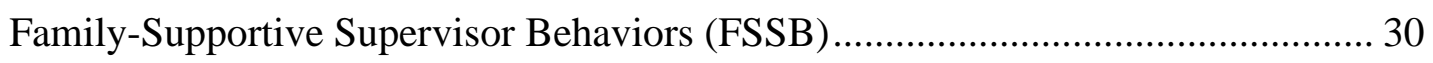

Perceived Supervisor Responsiveness (PSR) ............................................... 31

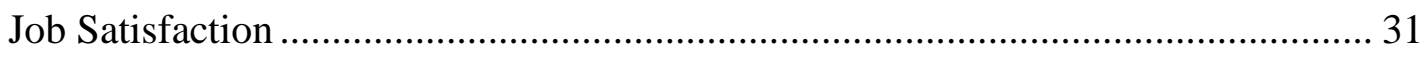

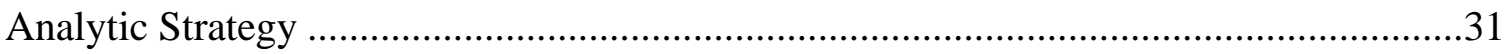

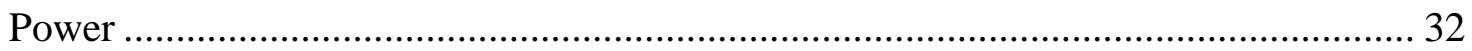

Multi-level measurement model ............................................................................ 33

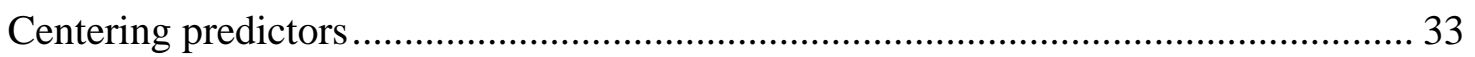

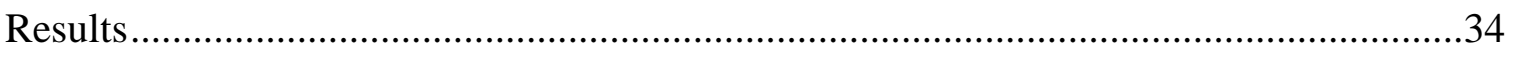

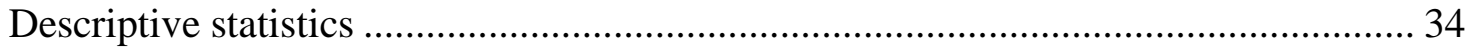

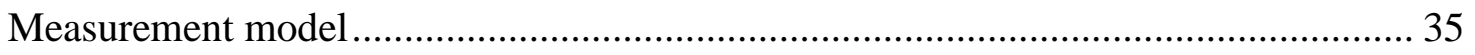

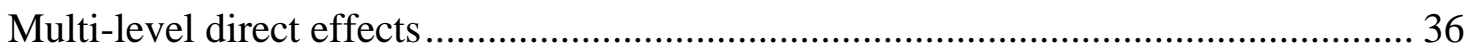

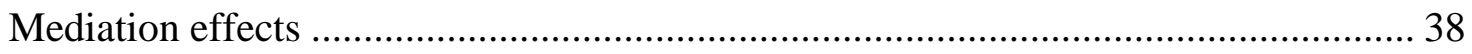

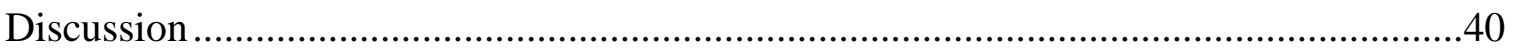

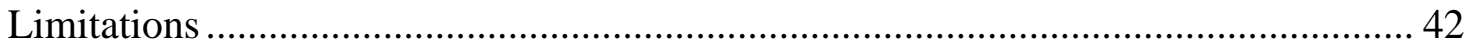

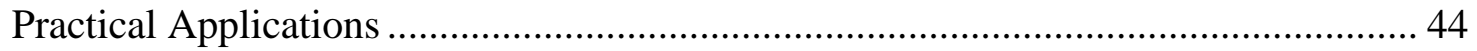




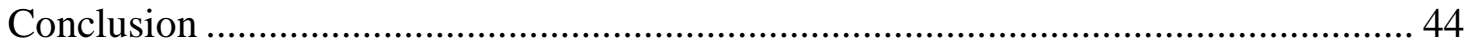

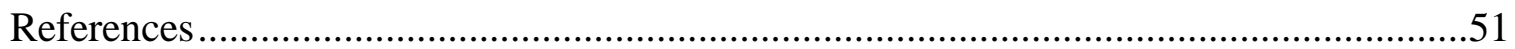


List of Tables

Table 1 Sociodemographics and Military Background Characteristics..........................46

Table 2 Descriptives and Correlations Among JobSat, FSSB, and PSR ........................47

Table 3 Results of a Multi-level Confirmatory Factor Analysis of FSSB and PSR........47

Table 4 Standardized Factor Loadings and Error Variances for a Multilevel Confirmatory Factor Analysis Model of Family Supportive Supervisor Behaviors (FSSB) and Perceived Supervisor Responsiveness (PSR) ..................................................................48

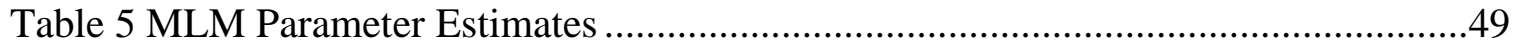

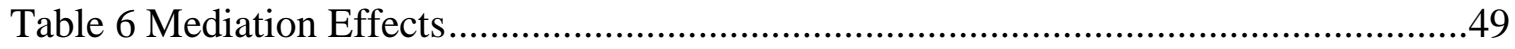


List of Figures

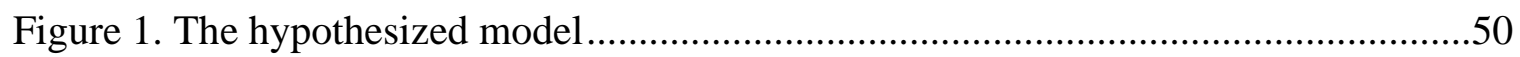


Introduction

The effects of positive working relationships between supervisors and employees have been studied for over 70 years by social and organizational scholars across an array of disciplines (Hogg, 2010). As far back as the Ohio State program of leadership studies conducted in the 1940s, a relational orientation toward employees emerged as a key factor of successful leadership (see Stogdill, 1974). Various forms of supervisor support, which contribute to a quality relationship with employees, consistently show positive effects on employee work experiences and perceptions of well-being (e.g. Gilbreath \& Benson, 2004; Kossek et al., 2018; Sparr \& Sonnentag, 2008; Thomas \& Ganster, 1995; van Dierendonck, Haynes, Borrill, \& Stride, 2004). Relatively early research on supervisor support showed positive relationships with both physiological health (House \& Wells, 1977) and psychological health (G. Blau, 1981; Caplan, Cobb, Harrison, \& Pinneau, 1975). More recently, meta-analytic work by Ng and Sorensen (2008) supports broad conclusions regarding the positive relations between general supervisor support and employee job satisfaction, perceived organizational support, and affective commitment.

As a result of the changing nature of the interface between work and non-work life, other forms of more specific support have emerged as important factors influencing the quality of employee's experiences at work. Key among these specific forms of support is family-specific supervisor support (Hammer, Kossek, Zimmerman, \& Daniels, 2007). As family life is increasingly recognized as a primary contributor to employees' well-being, organizational and supervisor support for workers' family life has become increasingly valued by both those seeking employment and those in charge of 
organizational design. Crain and Stevens (2018) recently conducted a review of the family-supportive supervisor behaviors (FSSB) literature and outlined the many employee outcomes that have been considered in the field of FSSB research including work variables (e.g. job satisfaction, commitment, engagement, motivation, turnover intentions), health markers (e.g. sleep, cardiovascular health, stress), and work-family experiences (e.g. work-to-family, family-to-work). The nomological net of FSSB shows that family-support is a proximal indicator of the quality of employee experiences at work. Crain and Stevens note, however, that the bulk of research on FSSB is crosssectional and call for methodological advances in future research to better test and develop the model of FSSB put forth by Hammer and colleagues (2007).

The primary purpose of this study, therefore, was to extend our understanding of the means through which FSSB exerts its positive influence on employee outcomes. This aim was accomplished through a few key features of this study. First, this study consisted of a within-person examination of the effects of FSSB on job satisfaction. There are approximately twelve published studies that have examined the relationship between FSSB and job satisfaction (denoted with an asterisk in the references) and only one is longitudinal (Allen, 2001; Bagger \& Li, 2014; Behson, 2005; Breaugh \& Frye, 2007; Frye \& Breaugh, 2004; Hammer, Ernst Kossek, Bodner, \& Crain, 2013; Hammer, Kossek, Yragui, Bodner, \& Hanson, 2009; Hwang \& Ramadoss, 2017; Odle-Dusseau, Britt, \& Greene-Shortridge, 2012; Thomas \& Ganster, 1995; Thompson \& Prottas, 2006; Wang, Walumbwa, Wang, \& Aryee, 2013). Therefore, this study shines the first empirical light on the extent to which daily fluctuations in employee's FSSB perceptions influence daily job satisfaction. Establishing a link between daily FSSB and a daily 
measure of job satisfaction is an important empirical and theoretical advancement for the FSSB literature, it acts as a test of criterion validity for FSSB within-person. Job satisfaction is an important index representing numerous feelings about the extent to which a person's work situation fulfills key needs and matches their values (Locke, 1969). Daily fluctuations in employee experiences with their supervisor (e.g. FSSB) are theoretically expected be related to daily fluctuations in job satisfaction.

While FSSB is expected to relate to job satisfaction at the day level, a natural follow-up question is why? This study takes a step toward answering this question by using a construct from the relationships literature - perceived responsiveness (Reis \& Gable, 2015). Perceived supervisor responsiveness (PSR) is theoretically and empirically positioned in this study as a positive relational outcome of supervisor support and which therefore accounts for the resulting uptick in job satisfaction. As Crain and Stevens (2018) note, most of the tested mechanisms of FSSB have been examined with constructs characterized by over-lapping criterion space (e.g. work-family conflict mediating FSSB effects). In the relationships science literature, perceived responsiveness is theoretically positioned as a key mediator of the effects that a partner's behavior has on individual and relational outcomes. In this study, PSR concerns the extent to which an employee feels valued, understood, and cared for by their supervisor. Taken together, novel methods (within-person) and a novel mediating construct (i.e. PSR), constitute a unique approach from which to better understand FSSB.

A review of the literature begins with job satisfaction to highlight what makes job satisfaction a useful daily outcome in this study. FSSB is then described and relevant literature is outlined to support hypotheses concerning FSSB as a daily phenomenon. 
PSR, on the other hand, remains currently unvalidated and is yet to be quantitatively evaluated. As such, research from two distinct psychological literatures - interpersonal relationships and leadership - will motivate hypotheses regarding PSR as a daily representation of employee's perceptions of the quality of their working relationships with their supervisors.

\section{Theory and Literature Review}

\section{Employee Job Satisfaction}

Employee job satisfaction is the most frequently examined and thoroughly researched job attitude in the organizational sciences (Judge, Weiss, Kammeyer-Mueller, \& Hulin, 2017). Conceptualized as a dynamic process of cognitive and emotional evaluation, job satisfaction concerns the extent to which the job and work environment align with basic values (e.g. justice) and meet basic needs (e.g. growth, camaraderie) (Locke, 1969; Seashore, 1974). In other words, the extent to which the work environment is experienced as an aid or a detriment to individual goals or standards is captured in the subjective assessment of job satisfaction. In his seminal work on job satisfaction, Locke (1976) defined job satisfaction as "a pleasurable or positive emotional state resulting from the appraisal of one's job or job experiences" (p. 1304). Such a broad appraisal is likely influenced by many factors comprising an individual's experiences and, accordingly, Seashore (1974) outlined a heuristic dissection of the variance in job satisfaction as $40 \%$ attributable to objective components of the environment, $30 \%$ individual differences such as personality and demographics, $20 \%$ to state-like individual attributes, and 10\% stochastic error. Recent work largely supports these heuristic proportions but show that even the extent to which objective components of the 
workplace influence job satisfaction may be driven by individual differences regarding occupational and organizational self-selection.

One cross-sectional meta-analysis showed approximately $10-25 \%$ of the variance in job satisfaction was accounted for by positive or negative affect (Connolly \& Viswesvaran, 2000), lending support for the notion that relatively stable affective patterns play a role in subjective assessments of job satisfaction. Another meta-analysis of the longitudinal test-retest stability of job satisfaction found a correlation confidence interval of .44 to .48 , indicating that approximately $20 \%$ of the variance in job satisfaction is stable over time (Dormann \& Zapf, 2001). The same authors found in a sub-sample of their meta-analytic results that the difference in test-retest correlations between those who stayed on their job and those who left their job was approximately .13, this small difference indicating the transportability of job satisfaction within-person despite organizational change (Dormann \& Zapf, 2001). To provide clarity on the extent to which job satisfaction is independent of job characteristics, Dorman and Zapf (2001) also conducted a primary study consisting of a longitudinal examination of workers in Germany following the reunification of the East and West, and found that that the zeroorder correlation between job satisfaction and job characteristics in 1990 and 1995 of .29 dropped to -.04 after controlling for job content and job stressors. Rather than conclude that job content and stressors drive change in job satisfaction, however, the authors point to individual differences in self-selection of organizations and occupations as a driving mechanism of the extent to which job factors play a role in job satisfaction. Research on the daily variability of job satisfaction shows that within-person factors are important to consider as well. Two daily-survey studies showed within-person variance in job 
satisfaction accounting for over $30 \%$ of the overall variance (Ilies \& Judge, 2002; Ilies, Wilson, \& Wagner, 2009), meaning that a significant proportion of job satisfaction may be attributable to dynamic influences occurring within employees each day. Altogether, these selected studies show that job satisfaction is a dynamic construct that is influenced to a large extent by the interaction between individual differences and environmental factors. Many more proximal indicators of job satisfaction have been examined, however, and illuminate the extent to which job satisfaction is a product of various organizational and interpersonal factors, individual differences notwithstanding.

For example, Humphrey, Nahrgang, and Morgeson (2007) conducted a comprehensive meta-analysis of job characteristics and found evidence that motivational characteristics (e.g. autonomy, skill variety, task complexity) accounted for $34 \%$ of the variation in job satisfaction and that, partialling out motivational characteristics, social characteristics (e.g. interdependence, social support) accounted for $17 \%$ of the variance in job satisfaction. For the purposes of this study, what this meta-analysis shows is that many organizational factors can indeed influence job satisfaction. What this study lacks, however, is an examination of what is widely known as a critical determinant of employee outcomes at work, namely, the quality of the supervisor-employee relationship.

Many studies have shed light on the importance of supervisor-employee relationships for job satisfaction. For example, Leader-member exchange (LMX), measures of which commonly include items such as, "How well does your leader understand your job problems and needs?”, and, “How well does your leader recognize your potential?", is the eminent construct and measure of supervisor-employee relationships (Erdogan \& Bauer, 2014), and hundreds of studies have examined this 
construct of LMX. Janssen and Van Yperen (2004) found correlational evidence of a positive relationship between LMX and job satisfaction $(\beta=.27)$, above and beyond the positive effects of mastery orientation, a key individual difference variable associated with overall job satisfaction. Lapierre and Hackett (2007) employed a meta-analytic structural equation model to assess a reciprocal process whereby organizational citizenship behaviors (OCB) led to LMX $(\beta=.23)$ and LMX led to increased job satisfaction $(\beta=.44)$, which subsequently led to more OCB $(\beta=.23)$ and therefore LMX. Interestingly, this study shows the reciprocal effects that indicators of job satisfaction, such as relational quality with one's supervisor, and outcomes of job satisfaction, such as OCB, have on one another. Such reciprocal processes lend further support for the dynamic nature of job satisfaction, as well as insight into how job satisfaction may stoke itself within some employees.

In addition to LMX, general supervisor support also shows positive relations with job satisfaction. Smith, Organ, and Near (1983) found that leader supportiveness, a measure derived from the Ohio State Leader Behavior Description Questionnaire, was related to job satisfaction $(\beta=.22)$ in a sample of banking employees. Baruch-Feldman, Brondolo, Ben-Dayan, and Schwartz (2002) found that general supervisor support positively related to job satisfaction $(\beta=.21)$, above and beyond other sources of support including support from family and coworkers, in a cross-sectional study of traffic enforcement agents. Furthermore, Judge and Hulin (1993) conducted a factor analysis of the various components which are commonly assumed to comprise job satisfaction (supervision, work itself, co-workers, pay, promotion opportunities) and found that satisfaction with supervision was the second most strongly related factor among those 
examined, and also discovered in their sample that overall job satisfaction accounted for approximately $30 \%$ of the variance in satisfaction with supervision. This proportion is relatively consistent with the coefficients previously outlined. The key takeaway from these selected studies is that supervisor-employee relationship matter for employee job satisfaction.

Assessing outcomes of job satisfaction is a complex task due to the welldocumented weak relationship between broad attitudes and specific behaviors (see Ajzen \& Fishbein, 2005 for a discussion). The fact that attitudes often show weak relations with behaviors, however, doesn't mean that attitudes don't exert meaningful influences on behavior, but rather that situational factors, trait-like individual differences, and state affect, among others, interact with and situationally condition attitude-behavior causal flows (Fishbein \& Ajzen, 1972). With this caveat in mind, job satisfaction nevertheless continually shows relationships with key organizational outcomes as shown in metaanalytic work including absenteeism frequency $(r=-.34)$ and duration $(r=-.15)$ (Scott \& Taylor, 1985), turnover intentions $(r=-.32)$ (Carsten \& Spector, 1987), and job performance $(\rho=.30)$ (Judge, Thoresen, Bono, \& Patton, 2001). Early primary research established a link between job satisfaction and interpersonal OCBs in a sample of employees across a variety of organizations (Smith et al., 1983). Judge and Hulin (1993) found that job satisfaction relates to subjective well-being $(\beta=.31)$ in a structural equation model of cross-sectional survey data from a clinical and health maintenance organization. As described earlier, meta-analytic evidence shows that job satisfaction is related to $\mathrm{OCB}(\beta=.23)$ indicating that as employees are increasingly satisfied with their jobs they are more likely to report exhibiting extra-role behaviors that benefit their fellow 
employees and the organization at large (Janssen \& Van Yperen, 2004), although the opposite could be true as well, with the results of extra-role behaviors (or the affordance of such behaviors), leading to job satisfaction. Ultimately, employee job satisfaction matters for well-being, matters for the desire to continue employment with an employer, influences the ways in which employees treat each other at work, and the amount of time employees spend at work. For the purposes of this study, job satisfaction is leveraged as a subjective index of overall feelings about the quality of affairs at work. As such, indicators of the availability and provision of supervisor support and the extent to which employees feel that their relationship with their supervisor is in good standing should, theoretically, influence daily variation in job satisfaction.

\section{Family-Supportive Supervisor Behaviors}

As previously noted, research on supervisor support beginning in the 1970s (see Cohen \& Wills, 1985) showed benefits to employees. The steady stream of recent research, furthermore, continues to elevate the importance of supervisor support across diverse settings including among workers who do their work independently from direct supervision such as in-home caregivers (e.g. Li, Shaffer, \& Bagger, 2015). Over time, however, it was noted that domain-specific support exhibited by supervisors, for example family-specific support, would provide benefits to employees above and beyond general support (Hammer et al., 2009). The organizational literature is now replete with studies of the adverse effects of conflict between an employee's family life and work life (see

monograph review by Eby, Casper, Lockwood, Bordeaux, \& Brinley, 2005). Examples of the outcomes of conflict between work and family roles include negative associations with job satisfaction as found in a meta-analysis conducted by Kossek and Ozeki (1998), 
and safety behavior among hospital workers (Cullen \& Hammer, 2007), as well as positive associations with stress and depression among studies reviewed by Allen, Herst, Bruck, and Sutton (2000). Family-specific supervisor support is positioned as a proximal lever to reduce family and work life conflict. As far back as 1989, Shinn, Wong, Simko and Ortiz-Torres (1989) incorporated measures of family-support in their operationalization of supervisor support. Thomas and Ganster (1995) used the measure of family-specific support described by Shinn et al. (1989) to demonstrate the importance of supervisor support for a variety of employee outcomes including work-family conflict and non-family outcomes such as control and job satisfaction. Since then, family-specific supervisor support has generated much research interest.

Hammer and colleagues (2007) provided the first detailed account of the importance of family-supportive supervisor behaviors (FSSB). They drew on focus group research, examples of informally generated measures of organizational and supervisor support for family life, as well as the literature on social support in general, to outline a multi-level model of FSSB in a dynamic workplace environment (Hammer et al., 2007). Furthermore, Hammer et al. (2007) outlined four underlying dimensions that now formally constitute FSSB: emotional support, instrumental support, role model behaviors, and creative management of work. Emotional support constitutes the degree to which a supervisor cares for their employees and listens well. Instrumental support is characterized by proactive behaviors aimed at providing resources to employees through scheduling and flexibility, putting into practice organizational policies and resources when beneficial, and accommodating employee's family responsibilities in general. The role modeling component of FSSB is self-evidently named, with supervisors visibly 
enacting the kinds of work-family supportive practices that set a family-friendly climate in the workplace and contribute to a work-family friendly culture. Examples of rolemodeling include leaving work on time, taking time off to attend to children's activities, and communicating these behaviors to employee's at work in order to set a familyfriendly precedent. Finally, creative management simply means finding ways to organize work in such a manner that the organization and/or work-group benefit alongside the employee. Examples of creative management include cross-training employees so that one may cover for another in the case of a family emergency, or reworking employee schedules to fit both organizational needs and employee family responsibilities. Crosstraining benefits the organization by creating a more well-trained and engaged employee base in general and employees benefit by the addition of some latitude regarding their work if emergencies arise. Theoretically, Hobfoll's (1989) conservation of resources theory is often leveraged to explain the positive effects of FSSB on employee work experiences. Within the conservation of resources theoretical framework, FSSB are frequently considered a resource which employees are able to draw upon in order to effectively manage work and family responsibilities and role expectations with less of the accompanying strain that might otherwise arise as employee's seek to balance their roles in both environments (Kossek et al., 2018; Matthews, Mills, Trout, \& English, 2014; Matthews \& Toumbeva, 2015).

Following the lead of early conceptual work, FSSB has generated much research interest in the past decade and has demonstrated important relationships with employee outcomes (Crain \& Stevens, 2018). Hammer and colleagues have generated formally validated measures of FSSB in both long-form (Hammer et al., 2009) and short-form 
(Hammer, Kossek, Bodner, \& Crain, 2013). In both measure validation studies, the authors found FSSB positively related to job satisfaction (accounting for incremental variance above general supervisor support) and negatively related to turnover intentions (Hammer et al., 2013, 2009). Since the development of these measures, a variety of employee outcomes have been tested in conjunction with FSSB including disengagement and exhaustion among white-collar corporate workers (Koch \& Binnewies, 2015), work engagement and subjective well-being in samples of employees from a variety of industries and backgrounds (Matthews et al., 2014), LMX and family-supportive organization perceptions in a 3-wave lagged study of Mturk respondents (Matthews \& Toumbeva, 2015), satisfaction with work-family balance in a sample of employees across 13 companies and a variety of industries in countries across South America (Las Heras, Bosch, \& Raes, 2015), prosocial motivation at work among a sample of 2046 employees from Brazil, Kenya, the Netherlands and the Philippines (Bosch, Heras, Russo, Rofcanin, \& Grau i Grau, 2018), and work-to-family conflict and turnover intentions among gradeschool teachers (Hill, Matthews, \& Walsh, 2016). Furthermore, Mills, Matthews, Henning and Woo (2014) found direct and indirect effects of FSSB on employee performance as mediated by affective commitment and job self-efficacy. These selected studies, from among many, shed light on some of the basic relationships that FSSB shows with employee outcomes. As they are all cross-sectional survey studies, however, they do not foster an understanding of how FSSB works dynamically nor do they reveal anything about the interpersonal exchange which precedes the benefits that FSSB convey to employees. 
Some lagged survey research has been conducted which lends strength to hypotheses regarding stable relations over time between FSSB and employee outcomes. Bagger and Li (2014) found correlations between supervisory family support at time 1 on job satisfaction and turnover intentions measured two months later (study 1). OdleDusseau, Britt and Greene-Shortridge (2012) found direct effects of FSSB at time 1 on job satisfaction, organizational commitment, intention to leave, supervisor ratings of task performance, organizational support performance, and conscientiousness performance measured five months later. Kossek and colleagues (2018) collected data from 332 participants (61 supervisors and 271 employees) from twelve midwestern grocery stores, who had worked for the company for a minimum of two months, as part of a randomizedcontrol trial of a FSSB training intervention. Survey data were collected in two waves separated by 9 months. FSSB at time 1 was positively related to mental health, otherreported job performance, and job satisfaction, and negatively related to work-to-family conflict and turnover intentions 9 months later. FSSB, therefore, shows relatively stable and beneficial relations with employee outcomes over time.

In order to advance our understanding of the processes through which FSSB confer benefits to employees, more intensive methods must be employed. Understanding within-person processes may be accomplished using daily-diary studies, which provide insight into how much constructs of interest vary on a daily-basis. Using within-person repeated measures methods, this study will shed light on the extent to which FSSB is perceived to vary within-person at the day level as well as to what degree daily fluctuations in FSSB perceptions influence daily levels of job satisfaction. Taken together, the preceding review of the FSSB literature suggests the following hypothesis: 
Hypothesis 1: On days where participants report higher FSSB than their personal average, they also report higher job satisfaction than their average.

\section{Responsiveness}

The importance of a core principle of interpersonal responsiveness in all human relationships is defined and described by Harry T. Reis and his colleagues (Reis, Clark, \& Holmes, 2004; Reis, Crasta, Rogge, Maniaci, \& Carmichael, 2017; Reis \& Gable, 2015; Reis \& Patrick, 1996; Reis \& Shaver, 1988). It should be noted that the fundamental notion of parental responsiveness, and its importance for childhood development, was first outlined by John Bowlby and Mary Ainsworth (c.f. Bretherton, 1992), in their work on attachment theory. In short, they outlined and presented evidence for the importance of a mother's responses to a child throughout development and the various outcomes associated with different parental responsive behavior patterns (Bretherton, 1992). Presently, perceived responsiveness in interpersonal relationships has emerged from the field of relationships science as a defining feature of many of the dyadic processes that underpin relational phenomena (Clark \& Lemay, 2010). Perceived partner responsiveness is defined as, "a process by which individuals come to believe that relationship partners both attend to and react supportively to central, core defining features of the self" (Reis et al., 2004, p. 203), and is often operationalized as the extent to which a person feels understood, cared for, and valued by a significant other (Reis \& Patrick, 1996). In their review and development of a detailed process model of partner responsiveness, Clark and Lemay (2010) depict dyadic behavioral exchanges that unfold over time, and which consist of interpersonal expectations, perceptions, and of course actual behaviors on the 
part of both people in a relational context that, ideally, facilitate trust and liking-both key characteristics of a quality relationship.

Clark and Lemay's (2010) model lays out a combination of individual characteristics (e.g. one's personal history of relationships with others) along with current relationship attributes (e.g. relationship specific history of responsiveness) as key contributors to the perceived likelihood of the provision of responsive behaviors in a relationship setting. These historical perceptions further contribute to the extent to which exhibited behaviors by one person are perceived and accepted as responsive by another. For example, one's history with relationships (positive and negative) predict general perceptions that one's current partner will be responsive to their needs (likely or unlikely), which predicts the seeking out of responsive support, which subsequently influences the probability of responsive support by the partner (Clark \& Lemay, 2010). Furthermore, the extent to which any behavior is responsive to another depends on the context and interpersonal setting and individual differences. What may be considered responsive behavior coming from a coworker may be perceived as intrusive coming from a supervisor, and vice versa. Responsive behaviors may take many forms including various types of support (e.g. instrumental, emotional), positive communication, disclosure, affirmation of aspects of one's identity, attentiveness in listening, etc. (Reis et al., 2004).

One specific form of responsive interpersonal behavior that has received attention in the literature is the positive reactions from a significant other to the sharing of good news. Sharing good news with another in an intimate relationship, a behavior known in the literature as capitalization, has shown positive effects on positive affect (Gable, Reis, 
Impett, \& Asher, 2004), and sleep (Arpin, Starkey, Mohr, Greenhalgh, \& Hammer, 2018). What is interesting, however, is that when sharing good news is received and affirmed by another person, an increase in positive affect is experienced above and beyond the act of sharing good news in itself (Gable et al., 2004). Pertinent to this study, the behaviors outlined by Reis et al. (2004) such as instrumental and emotional support, along with specific examples of responsive behavior such as capitalization, all may contribute to the relationship between a supervisor and an employee to various degrees and at different points in time and contribute to the quality of the relationship felt by both parties in the supervisor-employee dyad.

As such, McCabe, Arpin, and Mohr (2016) made a case for considering responsiveness as a key characteristic of the relationships that employees form with their coworkers and supervisors. In alignment with Clark and Lemay's (2010) model, they describe how responsiveness develops between supervisors and employees over time (or does not) and the implications for responsive supervisor-employee relationships in terms of the likelihood of an employee soliciting and receiving support in times of stress. An employee who perceives their supervisor to understand their needs and care about them as a person is more likely to engage with their supervisor to receive support when needed. Whereas employees who are mired in an unresponsive relationship with their supervisor are more likely to seek other channels of support or simply lack support at all leading ultimately to experienced strain (McCabe et al., 2016). For example, an employee with family matters which conflict with work must request the latitude to attend to those matters from their supervisor. Whether they seek support right away, or wait until things get worse, or whether they seek support at all depends on their perceptions of the kind of 
support (if any) they might receive. Responsive supervisors consider the whole person when interacting with their employees, recognizing that the well-being and engagement of their employees depends on their relationship, and create an environment where support may be expected. Theoretically, however, supervisor-employee responsiveness does not only pertain to stressor-strain processes. And nor does it foster, as some might assume, codependent behavior. In fact, responsive relationships at work may also boost healthy independent adult functioning, which is, perhaps, especially important in an organizational setting. Research showing these effects is discussed next.

The adult intimate relationships literature teems with studies illustrating the positive effects of responsive partners and shows interesting possibilities for a more nuanced perspective on the development and subsequent benefits of quality supervisoremployee relationships. For example, across two laboratory and survey studies of couples, Feeney (2007) found correlational and causal evidence that responsiveness and secure attachment among couples lead to more independent functioning and independent goal pursuit and attainment. Specifically, survey responses from both partners on measures of responsiveness to needs, independent functioning within the relationship (self-efficacy, independent goal pursuit), and attachment style (approach vs. avoidant, secure vs. anxious), were related to self and other reported self-efficacy and selfconfidence which was interpreted as showing evidence for the benefits of secure positive relationships on optimal individual functioning (study 1). Furthermore, one's perceptions of their partners' responsiveness to their needs predicted independent activity and exploratory behavior in a puzzle solving laboratory task (study 1). In a second study of 163 couples, Feeney (2007) replicated the findings of the first study with a lagged survey 
and found also that perceived responsiveness related to self-reported ability to achieve goals and partner verbal descriptions of their other's independent goal striving (study 2). Another finding from study 2 was that the probability of achieving a self-set goal was increased in those who, 6 months prior, had reported higher perceived responsiveness (Feeney, 2007; study 2). Intuitively, it might be expected that secure relationships prevent independent functioning and behavior, but that assumption is challenged in these studies conducted by Feeney (2007), who presents evidence that secure relationships provide a foundation upon which people feel more comfortable exploring their environment and acting on their own interests and compulsions.

In a similar manner, it may be that employees who perceive their supervisors as responsive to their needs likewise feel empowered to operate independently as needed and enact strategies necessary to achieve their goals. Meta-analytic evidence shows that employees who report autonomy, control, and participative decision-making at work, the presence of which may be perceived as a result of supervisors who lend employees their support for independent functioning, are related to high job satisfaction, commitment, performance, and motivation, along with low role ambiguity, role stress, and intentions to quit (Spector, 1986).

Indeed, two primary studies show how supervisors who demonstrate active listening and support for employee voice in an organization (behaviors which may be considered responsive) may benefit employee outcomes. In their first of two studies using a sample of German directors and department managers and their employee's, Lloyd, Boer, Keller and Voelpel (2015) found beneficial relations between perceived supervisor listening behaviors and employees organizational citizenship behavior (positive), 
emotional exhaustion (negative), and turnover intentions (negative). In their second study, they replicated these results with a larger sample of German employees from a variety of companies and extended their model to show that positive and negative affect mediates the relation between perceived supervisor listening and emotional exhaustion, turnover intentions and organizational citizenship behaviors (Lloyd et al., 2015). A related study conducted by Janssen and Gao (2015) examined 337 supervisor-employee pairs to illuminate the relation between a measure of "supervisory responsiveness" (operationalized as the perceived degree of support for employees voicing their input) and self-reported status perceptions and voice behavior. The authors found evidence for direct positive relationships between supervisory responsiveness and employee's perceived status and voice behavior (Janssen \& Gao, 2015). The authors also found a significant indirect relation between supervisory responsiveness and voice behavior as mediated through perceived status, indicating that employee's status perceptions are enhanced through their perceptions of their supervisor's support of their voice.

What should be taken away from this account of responsiveness in relationships is the assumption that all behaviors enacted in a relationship setting (e.g. supervisorsemployee) can be characterized by the degree to which they are responsive to the other person's values, needs, and expectations in terms of biological, cognitive, and emotional factors. This all-encompassing characteristic of responsiveness in relationships is advanced by Reis et al. (Reis et al., 2004) through the use of the following metaphor. They state that behaviors exchanged in relationship are as varied as the trees in a forest, but, just as each variety of tree shares a common "treeness" with other types of trees, all relationship behaviors share the basic mark of responsiveness (p. 202). 
Linking PSR to employee outcomes through LMX theory

LMX stands as the second most studied leadership construct in the organizational sciences (Avolio, Sosik, Jung, \& Berson, 2003) and is the foremost theory regarding relationships between leaders (supervisors) and employees (Erdogan \& Bauer, 2014). LMX theory began with the applications of role theory and social exchange theory to the supervisor-employee dyad (Sparrowe \& Liden, 1997). Role theory, in this context, outlines the development of an employee role within the organization as a result of a series of interactions between a supervisor and an employee which culminate into a set of norms between both parties that define the employee's expected role behaviors from the perspective of both parties (Graen, 1976). Kahn and colleagues outline role behavior as "system relevant, and which is performed by a person who is accepted by others as a member of the system" (1964, pg. 18). Thus, a supervisor initiates role-forming activities by delegating responsibilities and tasks followed by employee responses and behaviors which lay a foundation for the subsequent long-term role expectations between the supervisor and employee (Graen, Dansereau, Minami, \& Cashman, 1973; Graen, Orris, \& Johnson, 1973). When expectations are consistently met (i.e. responsive), mutual trust between the supervisor and employee develops over time (Bauer \& Green, 1996). As such, trust and relational behavior extending beyond the formal job contract is a defining characteristic of high LMX (Dienesch \& Liden, 1986). This feature of LMX theory constitutes a direct connection to theorizing and model development conceived by responsiveness researchers (e.g. McCabe et al., 2016).

Furthermore, as a derivative of social exchange theory (P. M. Blau, 1964; Emerson, 1976), which dictates reciprocal transactions as a key concept in relationship 
formation, LMX is thought also to depend on the characteristics of exchanges between supervisors and employees. In addition to the role-forming processes described above, supervisors are positioned to provide important resources to employees including various forms of support. For example, Bagger and Li (2014) relied on social exchange theory to hypothesize the mediating effects that LMX would have on the relationships between supervisor family support and job satisfaction and turnover intentions. Perceptions of supervisor family support, the authors found, exhibited lagged relations with both LMX as well as positive outcomes (Bagger \& Li, 2014). On the other hand, employees provide leaders with desirable benefits as well such as commitment to the work and citizenship behaviors. These mutual benefits underlying interdependence is an important notion of social exchange theory as full independence or dependence do not characterize social exchange (Cropanzano \& Mitchell, 2005). These kinds of exchanges build trust and foster higher LMX between supervisors and employees such that they stop "keeping count" of exchanges and may eventually act independently for the benefit of the other without explicitly expecting reciprocation (Erdogan \& Bauer, 2014). Acting on behalf of another independently in circumstances of high-LMX is consistent with Clark and Mills (1993) work outlining the differences between exchange and communal relationships. In exchange relationships, benefits bestowed by one party are expected to be reciprocated according to shared norms regarding timeliness and equivalence. Exchange relationships align with how low or average LMX is described, as defined by formal job descriptions or expectations. Communal relationships, on the other hand, are characterized by behaviors and benefits bestowed on behalf of another aimed at their general well-being 
and without explicit debts incurred-a la high-LMX (Clark \& Mills, 1993; Liden, Sparrowe, \& Wayne, 1997).

A couple of examples highlight how role formation and social exchange operate between supervisors and employees. Take for example a supervisor who sets up a new employee with specific work tasks and responsibilities and whose employee in turn responds with work products that exceed their supervisor's expectations. Trust is fostered, and the supervisor may thereafter outline a more important role for that employee as well as perceive the possibility of a closer relationship. On the other hand, an employee who produces average work products and reciprocates in normatively expected manners will more likely see their role outlined by their supervisor consistent with their job description and subsequently experience average LMX. Consider another common example, an employee reaches out to a supervisor for assistance with juggling their current workload and the recent and unexpected circumstance of a family member in need. A supervisor who responds with care and concern and is flexible regarding work begets trust and appreciation from the employee while a supervisor who responds with a lack of those characteristics would not. Role expectations and the quality of the relationship between a supervisor and employee, therefore, develop as a result of the degree to which employees respond to supervisor expectations and as a result of the degree to which supervisors respond to employee efforts at work as well as other basic needs. The latter is an important component of this role-defining process, a supervisor who does not respond adequately to the high-quality work of an employee or fails to create trust when employees come to them with their needs will stifle the development of high-quality relationship. 
Meta-analytic findings show that some of the outcomes positively related to high LMX include satisfaction with supervision, job satisfaction, organizational commitment, organizational citizenship behaviors, positive justice perceptions, empowerment, and job performance (Dulebohn, Bommer, Liden, Brouer, \& Ferris, 2012; Gerstner \& Day, 1997; Ilies, Nahrgang, \& Morgeson, 2007; Lapierre \& Hackett, 2007). Furthermore, LMX has been shown to be positively related to engagement as mediated by boosts in employees' access to key resources such as autonomy, developmental opportunities, and social support (Breevaart, Bakker, Demerouti, \& van den Heuvel, 2015). And direct links between LMX and lower role stress (i.e. role ambiguity and conflict) and subsequent burnout show the positive effects of LMX on well-being (Thomas \& Lankau, 2009). In short, the LMX literature contributes strong empirical support for the importance of supervisor-employee relationships for employee job attitudes and well-being.

The purpose of outlining LMX theory and literature is to show what has been considered and studied regarding the formation and presence of quality relationships between supervisors and employees in order to establish a theoretical and empirical base from which to examine PSR. This review supports the notion that it is useful to characterize exchanges between supervisors and employees which lead to high-LMX as mutually responsive such that they foster feelings of being understood, cared for, and valued. Measures of LMX include items related to trust, backing each other up when the other is absent, and overall quality of the relationship from the respondent's perspective (either the supervisor or the employee). Support for employee's needs, such as latitude for family role responsibilities, is a common element of high-LMX formation, especially when the relationship is of a quality exceeding that which is prescribed in by the formal 
organizational roles. Indeed, Morganson, Major, and Litano (2017) found LMX negatively related to work interference with family and positively related to perceptions of managerial support for family in a sample of 765 information technology employees. Therefore, it is expected that other measures of relationship quality, such as PSR, will relate to employee workplace outcomes in a similar manner as have measures developed to study LMX. A first step in validating a measure of PSR is to examine how it relates to well-established workplace variables (i.e. criterion related validity). Job satisfaction suits this task well. This review of the responsiveness and LMX literatures, therefore, motivates the following hypothesis concerning PSR:

Hypothesis 2: On days where participants report higher daily PSR, they also report higher job satisfaction.

\section{PSR as a relationship mechanism}

One of the aims of this study is to shed light on the underlying mechanisms that contribute to the positive effects shown in research on FSSB. Affective events theory (Brief \& Weiss, 2002; Weiss \& Cropanzano, 1996) and models of how responsive behaviors translate into perceptions and subsequent outcomes (Reis \& Gable, 2015) explain how perceived supervisor support might translate into perceptions of PSR and influence subsequent outcomes. Weiss and Cropanzano (1996) state that, "our theory gives primary emphasis to the role of events as proximal causes of affective reactions and then as more distal causes of behaviors and attitudes through affective mediation" (pg. 31). In other words, behaviors precede affective reactions which in turn precede conscious attitudes. In terms of this study, perceptions of FSSB should lead to affective reactions in the form of PSR perceptions, which in turn should influence global 
evaluations of job satisfaction. Concerning the causal chain of events in responsive interactions, Reis and Gable (2015) outline a model whereby one's partner enacts responsive behaviors (i.e. understanding, validation, and caring), those behaviors then are experienced and perceived and subsequent relationship outcomes result (pg. 68).

As a measure of perceived supportive behaviors, FSSB constitutes a subjective assessment of the extent to which employees believe that their supervisor either does, or would, enact supportive behaviors related to their family and non-work life (Hammer, Kossek, Bodner, \& Crain, 2013). As such, one item from the scale includes, "[my supervisor] worked effectively with employees to creatively solve conflicts between work and non-work". PSR, on the other hand, assesses the affective quality of an employee's interactions with their supervisor. Perceived responsiveness may be conceptualized as a personal and subjective emotional reaction to the behaviors exhibited by another person. For example, one item from the PSR scale employed in this study is, "To what degree [do] you feel understood by your supervisor"? It follows theoretically, therefore, that FSSB, among other salient supervisor behaviors, should precede PSR at the day level. Furthermore, subsequent evaluations of one's work experiences (i.e. job satisfaction) are expected to be motivated by, to some degree, these primary perceptions of one's supervisor's behaviors (FSSB) and reactions (PSR). Given the review of FSSB, PSR, and relevant theories of events and affect, the following hypothesis is advanced:

Hypothesis 3: PSR will mediate the daily relationship between FSSB and job satisfaction. 
Figure 1. Depicts the overarching model proposed herein along with all three hypotheses.

\section{The utility of daily survey methodology}

Proximal processes are important to those interested in advancing theory and developing interventions that work. Interpersonal behaviors and their accompanying immediate and reciprocal affective reactions are two of the most proximal phenomena of interest for all psychological theories. Implicit to most psychological theories and methods of testing those theories is the notion that broad attitudes relating to important concepts that involve the self (general feelings about work such as job satisfaction) form from daily behavioral or cognitive experiences which accumulate over time. The purpose of within-person methods looking at daily effects is to better understand what kinds of small effects may be adding up over time within a single person to affect broader perceptions, attitudes, and experiences. Furthermore, the ability to describe the process from behaviors to attitudes and subsequent experiences at work, as well as support these theoretical processes with empirical evidence, imbues practical value to both theoretical and applied work. As Crain and Stevens (2018) note, aside from intervention studies, research on FSSB consists largely of cross-sectional survey methods. FSSB research and practice will benefit from more intensive examination.

Already, in related scholarship, work-family theories and models have been examined within-person at the day-level. For example, employee daily self-reported job satisfaction after work has been shown to influence spouse-rated positive and negative affect at home (Ilies et al., 2009). And Ilies et al. (2009) found approximately 25-55\% of the variance among their study variables attributable to daily fluctuations. Butler, 
Grzywacz, Bass, and Linney (2005) found that daily fluctuations in demands and control at work were associated with daily perceptions of work-to-family conflict and found 45$69 \%$ of the variance in their study variables attributable to within-person variance. These examples show a precedent for significant fluctuations in perceptions among key variables within-person at the day level. It is expected that similar degrees of dailyfluctuations are present in the measures of FSSB, PSR, and job satisfaction.

\section{Methods}

\section{Study Overview}

The Study for Employment Retention of Veterans (SERVe; Hammer, Wan, Brockwood, Bodner, \& Mohr, 2018; Hammer, Wan, Brockwood, Mohr, \& Carlson, 2017), was a cluster randomized-control intervention study of post-9/11 civilianemployed former service members (hereafter referred to as "veterans") and their civilian workplace supervisors. The primary aim of SERVe was to develop and test the effectiveness of a training intervention provided to supervisors in order to increase their motivation and ability to provide support to veterans in their workplaces. Veteran designation was determined based on self-identification of veteran status and having served post-9/11. Participating veterans were required to work at least 20 hours per week for current employer.

Recruitment. The recruitment strategy entailed two main steps. First, organizations were recruited through several channels. Eligible organizations were identified through personal and professional contacts, veteran job fairs and other events including presentations at local, regional and state government meetings including various Chambers of Commerce and City Councils. Organizations recognized as likely to 
employ significant numbers of veterans (e.g. first responders, security firms) were targeted for recruitment as well. All organizations were based in a state in the Pacific Northwest. Then, within each participating organization, former service members were recruited for participation in the study. Forty-two organizations across industries including state and local government, law enforcement, education, manufacturing, construction, transportation, among others agreed to participate. Then, within those organizations, veterans were recruited to participate in the study along with their supervisors. Thirty-five organizations remained in the sample once veteran and supervisor recruitment was complete, the overall recruitment effort resulting in 509 veterans.

Participants. Pertinent to this specific study, however, veterans participating in the SERVe project were invited to participate in a parallel study of their family environment, known as the Daily Family Study (DFS). Of the 509 veterans who met the eligibility criteria for the larger SERVe study, 395 met eligibility criteria for the DFS (i.e., married or cohabiting with an intimate partner for at least six months), including that both the veteran and spouse had completed the SERVe baseline survey. Overall, 191 veterans consented and enrolled in the DFS.

The DFS was a 32-day web-based diary survey which veterans and their spouses or cohabitating partners completed before the training intervention was implemented with supervisors participating in the larger SERVe study. Although the DFS was conceptualized as a veteran-spouse/partner dyad study of the effects of daily home life on veteran outcomes, the daily survey consisted of workplace variables as well. For the purposes of this specific study, only veteran-reported variables were examined. 
As this study's hypotheses pertain to work experiences resulting from interaction with a supervisor, days on which veterans did not work or did not interact with their supervisors were excluded from analysis. The final analytic sample consisted of 155 veterans and 1054 eligible work days resulting in an average of 6.8 days per participant and a range of 1 to 22. Table 1 shows demographic and military descriptive statistics for this sample. Participants were predominantly male (90.0\%), white (85.2\%), and married (90.3\%), and had been enlisted (not an officer) in the military (80.6\%). A majority had completed college or a certificate program (68.4\%) and had deployed while serving in the military $(86.5 \%)$.

\section{DFS Procedures}

Surveys were administered online through a secure email link each day for 32days. The survey took 5-10 minutes to complete. Participants were required to complete the survey between 5:00 PM and 11:00 PM, after work and before bedtime. Shift workers (17\% of the sample) were allowed to take the survey each morning after their shift between the hours 5:00 AM and 11:00 AM. On average, DFS participants completed (22) survey days out of the 32 days, resulting in a total of $(n=3854)$ number of day-level responses and an average compliance of (69\%). As compensation for their time, veterans could earn up to $\$ 90$. All research protocols for the DFS were approved by an Institutional Review Board and the U.S. Army Medical Research and Material Command, Human Research Protection Office.

\section{Daily Measures}

Reliability, or internal consistency, was assessed using coefficient omega (McDonald, 1999), which is the proportion of variance in a factor attributed to "true 
score" in relation to error. It is commonly understood that Cronbach's alpha is a lower bound on reliability, and its use as a measure of reliability has been discouraged by psychometricians (Dunn, Baguley, \& Brunsden, 2014; Sijtsma, 2008). Omega has been touted as a more useful and accurate assessment of reliability (Revelle \& Zinbarg, 2008). Consistent with recommendations for calculating omega using the results of multi-level CFA outlined by Geldhof, Preacher, and Zyphur (2014), in which scales were congeneric, error variance was estimated at each level, and the latent factor was standardized, omega was calculated at each level for PSR and FSSB (see also Raykov \& Shrout, 2002; Yang $\&$ Green, 2010). These coefficients may be interpreted directly as an index of internal consistency for their respective measures (Revelle \& Zinbarg, 2008, p. 152) and consist of the proportion of variance accounted for by the "true score" of a factor.

Family-Supportive Supervisor Behaviors (FSSB). Each day, participants responded to the four-item measure of FSSB (Hammer et al., 2013) which measured their perceptions of FSSB for that day alone. The prompt for the survey was "How do these statements apply to your supervisor's behavior at work in the [reporting period]"? The dimensions and associated items assessed were: emotional support ("Made me feel comfortable talking to him/her about conflicts between work and non-work"), instrumental support ("Worked effectively with employees to creatively solve conflicts between work and non-work"), role modeling ("Demonstrated effective behaviors in how to juggle work and non-work issues"), win-win management ("Organized the work in my department or unit to jointly benefit employees and the company"). Each item corresponded with one of the underlying theoretical dimensions of FSSB and was measured on a 5-point Likert scale (1-strongly disagree to 5-strongly agree). Coefficient 
omega for level-0 was .85 (85\% of the variance in FSSB at level-0 was attributable to “true score"), and for level-1 was .98.

Perceived Supervisor Responsiveness (PSR). A 3-item measure of Perceived Partner Responsiveness (Laurenceau, Barrett, \& Pietromonaco, 1998), which was created as a result of early theorizing on the part of Reis and colleagues (e.g. Reis \& Shaver, 1988), was adapted for use in the current study. According to theoretical understanding, a person is expected to perceive another as responsive to their needs when they feel accepted, understood, and cared for (Reis \& Gable, 2015). As such, each item measured the extent to which respondents believed their supervisors exhibited responsive characteristics: acceptance (“To what degree did you feel accepted by your supervisor"), understanding ("To what degree did you feel understood by your supervisor"), care ("To what degree did you feel cared for by your supervisor", on a 5- point Likert scale (1-not at all to 5-extremely). Coefficient omega for level-0 was .88, and for level-1 was .98 .

Job Satisfaction. A single-item was used to assess participants daily satisfaction with their job (“[today] I was satisfied with my job”). This item was measured on a 5point Likert scale (1-not at all to 5-extremely).

\section{Analytic Strategy}

In this study, days were nested within participants which were nested within organizations. The foci of this study were within-person (level-0) variation and associations among the variables of interest. As such, multi-level models (MLM) with random effects were employed. All data manipulation and analyses were conducted in the R software platform for statistical analyses (R Core Team, 2018). Multi-level models 
were examined using the R package lme4, about which the authors have published in the Journal of Statistical Software (Bates, Mächler, Bolker, \& Walker, 2015). In order to assess the influence that various levels in a hierarchical data structure had on variables in this study, intercepts-only models were examined which partitioned the variance in variables according to the grouping structures specified. FSSB, PSR, and job satisfaction were all examined from a three-level variance components perspective and the variance accounted for by the organizational level was negligible $(<.000)$ for all three variables. Therefore, organizational nesting was ignored for all analyses.

\section{Power}

As is the case with all statistical hypothesis testing, power, or the probability of correctly rejecting a null hypothesis, is a necessary consideration in multi-level modeling. A general statement about power in MLM frequently espoused is that in general, it is better to have a greater number of groups (participants in this study) than number of observations per group (days in this study) (Hox, 2010; Tabachnick \& Fidel, 2013). Unlike ordinary least squares regression, however, power in MLM varies depending on the parameter being estimated, with random effects exhibiting lower power in general and the level of the effects under consideration (level-0 direct effects, level-2 direct effects, cross-level or interaction effects) also showing different power (Tabachnick \& Fidel, 2013). Also, power for hierarchical linear models has been observed to increase in general as intra-class correlations grow (Kreft \& DeLeeuw, 1998). Power in terms of level-0 coefficients is determined largely on total sample size (Hox, 2010), which in this study is the total number of days $(\mathrm{n}=1055)$. Power to test random effects, including variance and covariance parameters and their associated standard errors, as well as cross- 
level interactions, depends to a greater degree on the number of groups, with 100 or more groups (participants) and approximately 10 or more data points per group (days) considered ideal (Hox, 2010). The analytic sample in this study consists of 155 veterans who on average completed 6.8 criteria-eligible survey days - less than ideal but acceptable nonetheless given the lack of emphasis on random effects. Taken together, power for this study was deemed adequate for the significance testing of level-0 fixed and random effects.

\section{Multi-level measurement model}

Two assumptions regarding the constructs and measurement model in this study were statistically evaluated. First, it was assumed that FSSB and PSR constitute distinct, but related, constructs. Second, it was also assumed that construct distinctness between FSSB and PSR would be sustained at both level-0 and level-1. Measurement and construct validity were examined using a maximum-likelihood multi-level confirmatory analysis (ML-CFA) which has been outlined by Hox (2010). The results of the measurement model are discussed further below.

\section{Centering predictors}

Centering is a very important consideration in MLM and various approaches have major implications for coefficient estimations and interpretations (Kreft \& DeLeeuw, 1998). For level-0 hypotheses (day-level), including those involving mediation, personcentering is the indicated approach (Tabachnick \& Fidel, 2013; Zhang, Zyphur, \& Preacher, 2009). When modeling day-level effects and person-level effects through MLM, the aim is to control for between-person effects creating partial regression coefficients at the day-level. In other words, the goal is to isolate day-level relations 
among variables independent of the effect that an individual person's average report on the variable of interest has on day-level values. Thus, person-centering constitutes the method for parsing out between-person effects when within-person effects are of interest. Person-centering directly decomposes the relationship between the IV and DV into between and within components, a necessary condition for modeling level-0 (day-level) effects. Therefore, day-level variables were centered on person means, and person means were entered into the model as level-1 variables for comparative and interpretative purposes.

\section{Results}

\section{Descriptive statistics}

Table 2 shows the means, standard deviations, and correlations for the variables under consideration in this study. These descriptives are shown for person-centered, person-mean, and raw variables. Within-person correlations between job satisfaction and FSSB (.13) and PSR (.15) were between small and moderate in magnitude. The betweenperson (average across days) correlations between job satisfaction and FSSB (.48) was moderate to large in magnitude, and between job satisfaction and PSR (.62) was large. Differences in strengths of correlations at the within and between-person levels can be largely attributable to the fact that at the day level, scores on items are necessarily more likely to be influenced by error such as random response or transient error (Schmidt, Le, \& Ilies, 2003) while a person's average across days indicates more of a true score on the construct. As such, the greater the variance accounted for in a construct at the withinperson level (i.e. $\mathrm{ICC}_{1}$ ) the greater the correlation between constructs at that higher level will be (Bliese, Maltarich, Hendricks, Hofmann, \& Adler, 2019). 
Intercepts-only models were examined to assess the extent to which variance in each variable was attributable to person or day-level factors. The first model, an intercepts-only model of job satisfaction, showed an $\mathrm{ICC}_{1}$ of .65 , which means that approximately $35 \%$ of the variance in job satisfaction occurred within-person. Similarly, the $\mathrm{ICC}_{1}$ for PSR of .77 and for FSSB of .67 meant that $23 \%$ and $33 \%$ of variance occurred within-person for each variable respectively. These within-person variance proportions show the empirical necessity for examining this study's within-person hypotheses with MLM.

\section{Measurement model}

In order to assess the extent to which FSSB and PSR are distinct constructs a MLCFA was conducted to assess the factor structure of FSSB and PSR at the within and between-person levels simultaneously. Maximum-likelihood estimation was used in accordance with recommendations by Hox (2010) which consists of multiple steps, each step consisting of an incrementally more complex model. Model fit indices for each model are shown in Table 3. The in $\mathrm{R}$ package Lavaan was used to conduct the analyses (Rosseel, 2012). First, a benchmark model, a "null model”, which consisted of specifying a two-factor structure to the items at the within-person level and specifying no structure and zero variances at the between-person level, was estimated. This model did not fit the data well, $\chi^{2}(41)=2293.84, \mathrm{CFI}=.17, \mathrm{TLI}=.15, \mathrm{RMSEA}=.23, \operatorname{RMSEA}_{\mathrm{CI}}[.22, .24]$, signaling an important degree of variance explained at level-1. Next, an independence model was specified which consisted of the same level- 0 specification with the addition of estimated variances at level-1. The rationale behind this model is that, if it fits, then level-1 accounts for variance in level-0, but no factor structure underlies the items. This 
model also did not fit the data well, $\chi^{2}(34)=1271.22, \mathrm{CFI}=.67, \mathrm{TLI}=.59, \mathrm{RMSEA}=$ .19 , RMSEACI $[.18, .20]$. The penultimate model included the specification of a single latent factor at level-1. Relative to the previous models, this two-factor level-0 and onefactor level-1 model approached acceptable fit, $\chi^{2}(27)=265.14, p<.05$, CFI $=.95$, TLI $=.92, \operatorname{RMSEA}=.09, \operatorname{RMSEA}_{\mathrm{CI}}[.08, .10]$. The final model, however, in which the expected two-factor latent structure was specified at both levels, achieved acceptable fit, $\chi^{2}(26)=104.85, \mathrm{p}<.05, \mathrm{CFI}=.98, \mathrm{TLI}=.97, \mathrm{RMSEA}=.05, \mathrm{RMSEA}_{\mathrm{CI}}[.04, .06]$, and was significantly better fitting than the level-1 single-factor model, $\Delta \chi^{2}(1)=160.28, \mathrm{p}<$ .05. Therefore, the two-level two-factor measurement model was used to test this study's hypotheses. Table 4 shows the factor loadings and associated error variances and factor correlations.

\section{Multi-level direct effects}

Table 5 shows the results of each hierarchical model described next. A randomslopes model of job satisfaction regressed onto FSSB was examined. The level-0 fixedeffect between FSSB and job satisfaction was significant, $\gamma_{10}=.160, \mathrm{SE}_{\gamma}=.052,95 \% \mathrm{CI}_{\gamma}$ $[.056, .262], p<.001$; a positive deviation in FSSB on a given day was associated on average with a positive deviation in job satisfaction. This finding supported hypothesis 1 . The level-1 coefficient was significant as well, $\gamma_{01}=.561, \mathrm{SE}_{\gamma}=.083,95 \% \mathrm{CI}_{\gamma}[.397$, $.725], p<.001$, indicating that mean FSSB was positively associated with mean job satisfaction; thus, veterans who experienced higher FSSB across days also reported higher job satisfaction across days. Pseudo- $\mathrm{R}^{2}$ values were calculated with fixed-effects regressions according to the logic of Snijders and Bosker (1999). Using concepts and equations presented in Snijders and Bosker (1994), level-1 pseudo- $\mathrm{R}^{2}$ was calculated as 
.227 - indicating an approximately $23 \%$ reduction in the prediction error of job satisfaction at the between-person level with the addition of FSSB as a predictor at level0 and level-1. Using the logic of Snijders and Bosker (1994) once again, level-0 pseudo$\mathrm{R}^{2}$ was calculated as .176 - indicating an approximately $18 \%$ reduction in the prediction error of job satisfaction at the within-person level with the addition of FSSB as a predictor at level-0 and level-1. An alternative method of considering the variance accounted for at level- 0 alone described by $\mathrm{Xu}$ (2003), the ratio of reduction in withinperson error, was calculated as .017 , indicating that the residual within-person error variance was approximately $2 \%$ lower with FSSB added as a predictor.

Hypothesis 2 was tested with a random-slopes model of job satisfaction regressed onto PSR. The fixed-effect of within-person PSR and job satisfaction was significant, $\gamma_{10}$ $=.231, \mathrm{SE}_{\gamma}=.041,95 \% \mathrm{CI}_{\gamma}[.148, .316], p<.001$, on any day, veterans who experienced higher PSR also experienced higher job satisfaction, supporting Hypothesis 2. The level1 coefficient was significant as well, $\gamma_{01}=.564, \mathrm{SE}_{\gamma}=.056,95 \% \mathrm{CI}_{\gamma}[.454, .674], p<$ .001 , indicating that mean PSR across days was positively associated with mean job satisfaction across days. Using the same calculations referenced above, level-1 pseudo- $\mathrm{R}^{2}$ was calculated as .373 - indicating an approximately $37 \%$ reduction in the prediction error of job satisfaction at the between-person level with the addition of PSR as a predictor at level-0 and level-1. Level-0 pseudo- $\mathrm{R}^{2}$ was calculated as .288-indicating an approximately $29 \%$ reduction in the prediction error of job satisfaction at the withinperson level with the addition of PSR as a predictor at level-0 and level-1. The $\mathrm{Xu}$ (2003) pseudo- $\mathrm{R}^{2}$ value was .023 , indicating that the residual within-person error was approximately $2 \%$ lower with PSR added as a predictor. 
Mediation effects

Hypothesis 3 stated that PSR would mediate the relationship between FSSB and job satisfaction. Mediation was examined through the perspective afforded by two approaches, the first being likelihood ratio tests of adding predictors and the second being a statistical test of the mediation effect following the approach outlined by Zhang et al. (2009) and using statistical tools designed and described by Tingley, Yamamoto, Hirose, Keele, and Imai (2014). First, likelihood ratio tests were examined to determine the significance of adding each predictor to the other in models with job satisfaction as the outcome. Model 3 in Table 5 shows the results of a model of job satisfaction with both PSR and FSSB as predictors (at both between and within levels). This full model was compared to model 1 and model 2 via a likelihood ratio test. The full model accounted for significantly greater variance than a model with FSSB entered alone (model 1 in table 5), $\chi^{2}(2)=4.805, p>.05$, which demonstrated the incremental empirical value of PSR in accounting for variance in job satisfaction over FSSB. On the other hand, the full model did not account for significantly greater variance in job satisfaction over a model with PSR entered alone (model 2 in table 5), $\chi^{2}(2)=4.805, p>.05$, indicating that FSSB did not account for significant variance in job satisfaction over PSR. These results lend support to the notion that PSR soaks up the variance in job satisfaction accounted for by FSSB which suggests possible mediation.

In order to directly assess the mediating effect of PSR on the relationship between FSSB and job satisfaction, two regression models were examined following guidelines outlined by Zhang et al. (2009). The first model, a random-slopes model of PSR (the mediator) regressed on FSSB, showed a significant relationship, $\gamma_{10}=.510, \mathrm{SE}_{\gamma}=.030$, 
$95 \% \mathrm{CI}_{\gamma}[.450, .568], p<.001$, indicating that on days veterans experienced higher than average FSSB they also experienced higher than average PSR. The second model considered (model 3 in table 5) regressed job satisfaction onto FSSB and PSR, with PSR specified as a random effect. The partial regression coefficient for FSSB was not significant, $\gamma_{10}=.087, \mathrm{SE}_{\gamma}=.046,95 \% \mathrm{CI}_{\gamma}[-.004, .178], p=.061$, which, when compared to the random-effects model of FSSB and job satisfaction shows a decrease in the regression coefficient of approximately .080 ( $~ 50 \%$ reduction) with the addition of PSR as a predictor. PSR, on the other hand, significantly predicted job satisfaction, $\gamma_{20}=$ $.193, \mathrm{SE}_{\gamma}=.046,95 \% \mathrm{CI}_{\gamma}[.099, .290], p<.001$, which showed that, on average and controlling for FSSB, days on which veterans reported higher than average PSR they also reported higher than average job satisfaction.

Using the above two models, the mediation effect and associated confidence interval were generated with a quasi-Bayesian Monte-Carlo approach combined with robust (heteroskedasticity-consistent) estimators with 2000 samples using the mediate function within the "mediation" package (Tingley et al., 2014). Table 6 shows these results. The mediation effect of PSR at level-0 was significant, $\gamma_{\mathrm{m} 0}=.079,95 \%$ CI [.033, $.130], p<.001$. Combined with the fact that within-person FSSB was reduced to a nonsignificant (but not zero) effect, suggests that PSR mediates the relationship between FSSB and job satisfaction, supporting Hypothesis 3. At level-1 (between-person), the mediation effect of PSR was also significant, $\gamma_{\mathrm{m} 1}=.735,95 \%$ CI $[.504, .980], p<.001$. Given also that level-1 FSSB became a nonsignificant predictor of job satisfaction when level-1 PSR was entered into the model, suggests that PSR mediates the relationship between FSSB and job satisfaction between-people as well. 


\section{Discussion}

The research presented in this study investigated within-person relationships between FSSB and other positive employee experiences, namely PSR and job satisfaction. It was shown that days characterized by higher than average FSSB showed higher than average job satisfaction across veterans, supporting hypothesis 1. Likewise, days characterized by higher FSSB were also characterized by higher PSR; on average, employees experienced a greater sense that their supervisor was responsive to their needs on days where their supervisor demonstrated above average family-supportive behaviors. Hypothesis 3 advanced PSR as a mediator of the relationship between FSSB and job satisfaction - that veteran job satisfaction would be positively influenced by FSSB through their perception that their supervisor was responsive. This hypothesis was also supported. Overall, the results show support for the theoretically consistent idea that FSSB behaviors are perceived in large part by veteran employees as responsive to their needs and improve one's sense of job satisfaction.

These findings answer the call by Crain and Stevens (2018) to examine FSSB with a greater diversity of approaches "to better understand FSSB processes and interactions on a more micro and episodic level" (p. 881). Furthermore, the fact that so many studies of FSSB rely on cross-sectional research designs raises issues of common method biases in terms of theory development and testing (Podsakoff, MacKenzie, Lee, $\&$ Podsakoff, 2003). An important step in the testing and advancement of theory around FSSB is the use of measurement and analytic approaches that differ from those predominantly used in the published literature. This study leveraged a within-person design to test and advance FSSB theory, and the findings supported commonly held 
tenets of FSSB, namely that FSSB is positively related to beneficial job outcomes. Other benefits for future research of using experience sampling to understand FSSB and PSR as day-level constructs are presented below.

In addition to the relationships FSSB showed with PSR and job satisfaction, the within-person design shed new light on FSSB in other ways as well. First, it was shown that a relatively large proportion of variance in FSSB may be attributable to daily processes and perceptions, meaning there is empirical room for studying perceptions of FSSB as a daily generated phenomenon. Next, the four sub-dimensions of FSSB showed a similar pattern of factor loadings at both the within-person and between-person levels supporting the notion that the four underlying factors of emotional support, instrumental support, role modeling and win-win management operate in a congruent manner at both levels. This is useful evidence of construct validity of the FSSB scale for use in daily diary studies which might examine even more nuanced daily or weekly FSSB processes in future studies. For example, Ritter, Matthews, Ford, and Henderson (2016) examined the relationship between role clarity and conflict and job satisfaction over time to better understand how time influences employees' experiences of these constructs.

Furthermore, FSSB was shown to be psychometrically distinct from the measure of supervisor-employee relationship quality employed in this study, PSR, at both the within and between-person levels. At face value - considering the items - it was expected that these constructs would strongly correlate, and perhaps overlap to such a degree as to nullify the value of examining them in isolation. In contrast, FSSB and PSR showed their distinctness from an empirical perspective, and future studies might use PSR to examine other ways that FSSB positively influences employees' work and family life. 
In fact, this study was the first to examine the theoretical construct PSR empirically. (McCabe et al., 2016) theorized about the positive influence that perceived responsiveness in the workplace might have on employees' experiences. This study supports the idea that PSR is valuable for employees and influences perceptions of the quality of their experiences at work. From a measurement and methodological perspective, PSR shows utility as a construct of interest for future research. Validity evidence for PSR was shown in the form of uniqueness from a related construct (FSSB) and through positive relationships with theoretically related constructs (FSSB and job satisfaction). Hypothesis 2 stated that PSR would relate to job satisfaction within-person and was supported by the results. PSR seems worthy of future research considering employee's perspective of the quality of the relationship with their supervisor.

\section{Limitations}

Given that this study's within-person relationships were all examined on the same day, the design is essentially correlational despite the within-person analyses allowed by the repeated measures. All measures were taken at the same time and each time point constituted the basic unit of analysis. Therefore, caution should be taken in terms of assuming the direction of relationships among this study's variables. Theoretically, PSR can result from the effects of supportive behaviors exhibited by one's supervisor but perceiving one's supervisor as responsive could influence the solicitation of support on a given day, a circular phenomenon described by Clark and Lemay (2010) in their model of perceived responsiveness. Future research should attempt to tease apart the temporal relationship between PSR and FSSB empirically. On the other hand, what the methods employed in this study have as an advantage over a cross-sectional design is the ability to 
parse out the extent to which relationships among variables are the result of withinperson or between-person factors. In order to understand how processes unfold at the daily level it is useful to begin by taking a look at the extent to which variables covary within people across days. If a correlation occurs within the same person on different days that is a great place to start unpacking the causal mechanisms that might be at play through more intensive studies. Furthermore, realizing that certain positive experiences correlate at the day level is enough to design workplace interventions that highlight the importance of daily interactions, regardless of the specific causal mechanisms that might influence subjective experiences.

Another limitation in this study was the low average number of days reported on per participant. This was partially the result of many participants indicating that they did not interact with their supervisor on a given day, even if they had completed the rest of the survey. Low number of days per participant raises questions about both the power of day-level hypothesis tests but also about the observed relationships at the day level. In terms of power, FSSB became non-significant with the addition of PSR, but the coefficient did not drop to zero. It should not be taken as the case that FSSB does not influence job satisfaction within person accounting for PSR, it does, just not to the same extent or in the same manner.

A homogeneous and minority sample constitutes another limitation of this study in terms of generalizability. These results should not be taken for granted among women, people of color, people from different cultures, non-veteran populations, single people, blue-collar workers, or young workers, etc. The importance of FSSB and PSR for job satisfaction for any of these groups might differ from the results shown here. 


\section{Practical Applications}

One of the applications of this study is the idea that between-person levels of PSR and FSSB might be driven by daily perceptions of these behaviors. Within-person variance on both constructs indicated that people witness and feel varying degrees of support and responsiveness from their supervisors on a daily basis. Interventions targeting supervisor behaviors in a work context should discuss the fact that their daily behaviors matter to the quality of their employees' daily work experiences. And specific behaviors matter, FSSB is measured by asking employees about how their supervisor acted toward them or others at work regarding the balance between work and non-work life. Encouraging behavioral change among supervisors by focusing on specific behaviors to change is a practical and impactful intervention strategy (e.g. Hammer, Kossek, Anger, Bodner, \& Zimmerman, 2011). In terms of motivating change, knowing that daily behaviors matter to employees means that supervisors can be encouraged to focus on positive behaviors each day, and pay attention to ways they interact with and support their employees from the present moment moving forward.

\section{Conclusion}

Overall, this study contributes to the literature on employee perceptions of FSSB at work. It was shown that FSSB relates to PSR and job satisfaction within-person demonstrating that employees are sensitive to fluctuations in the extent to which their supervisor supports their non-work life each day. Future studies of FSSB may use the results of this study to justify the use of FSSB to examine more nuanced within-person relationships. Also presented in this study was evidence of the validity of PSR as a measure of employees' perceptions of the responsiveness of their supervisor. Future 
research may build on this work by examining how PSR relates to other theoretically related constructs. For example, it would useful and interesting to know how PSR differs in its relationships with outcomes compared to perceptions of coworker responsiveness. Taken together, the findings from this study may be used to encourage supervisors to focus on each day as they seek to engage and support their employees, knowing that their employees benefit from frequent and daily positive interactions. 
Table 1

Sociodemographics and Military Background Characteristics

\begin{tabular}{ll}
\hline Variable & $\mathrm{M}(\mathrm{SD}) / \%$ \\
\hline Age & $38.7(9.21)$ \\
Male & $90.0 \%$ \\
White & $85.2 \%$ \\
College/certificate graduate & $68.4 \%$ \\
Married & $90.3 \%$ \\
Number of children at home & $2.01(1.51)$ \\
Shift worker & $16.8 \%$ \\
Active in the military & $16.8 \%$ \\
Years in the military & $12.35(8.09)$ \\
Years in last/recent rank & $3.49(2.38)$ \\
Enlisted & $80.6 \%$ \\
Years since separated from military & $5.89(3.36)$ \\
Combat exposure & $71.7 \%$ \\
Deployment & \\
Ever deployed & $86.5 \%$ \\
Years since last deployment & $7.66(3.79)$ \\
Number of deployments since 9/11 & $3.20(2.76)$ \\
Last recent branch & \\
Army National Guard & $20.6 \%$ \\
Air National Guard & $7.7 \%$ \\
Army Reserves & $12.3 \%$ \\
Marine Reserves & $11.6 \%$ \\
Navy Reserves & $21.3 \%$ \\
Air Force Reserves & $5.8 \%$ \\
Air Force & $4.5 \%$ \\
Coast Guard & $1.3 \%$ \\
\hline Notes: N 155. &
\end{tabular}

Notes: $\mathrm{N}=155$. 
Table 2

Descriptives and Correlations Among JobSat, FSSB, and PSR

\begin{tabular}{|c|c|c|c|c|c|c|c|c|c|c|c|}
\hline Variable & Mean & SD & $\mathrm{ICC}_{1}$ & 1 & 2 & 3 & 4 & 5 & 6 & 7 & 8 \\
\hline 1. JobSat 0 & 0.01 & 0.62 & - & - & & & & & & & \\
\hline 2. JobSat $_{1}$ & 3.58 & 0.84 & - & .04 & - & & & & & & \\
\hline 3. $\mathrm{FSSB}_{0}$ & 0.00 & 0.48 & - & .13 & .00 & - & & & & & \\
\hline 4. $\mathrm{FSSB}_{1}$ & 3.57 & 0.77 & - & .04 & .48 & .01 & - & & & & \\
\hline 5. $\mathrm{PSR}_{0}$ & -0.01 & 0.50 & - & .15 & .00 & .48 & .02 & - & & & \\
\hline 6. $\mathrm{PSR}_{1}$ & 3.51 & 0.99 & - & .05 & .62 & .01 & .83 & .00 & - & & \\
\hline $\begin{array}{l}\text { 7. JobSat } \\
\text { (raw) }\end{array}$ & 3.59 & 1.06 & 0.65 & - & - & - & - & - & - & - & \\
\hline 8. FSSB (raw) & 3.57 & 0.92 & 0.67 & - & - & - & - & - & - & .37 & - \\
\hline 9. PSR (raw) & 3.50 & 1.11 & 0.77 & - & - & - & - & - & - & .50 & .76 \\
\hline
\end{tabular}

Notes: JobSat $=$ job satisfaction. FSSB = Family-Supportive Supervisor Behaviors. PSR $=$ Perceived Supervisor Responsiveness. $\mathrm{N}_{\text {day }}=1054 ; \mathrm{N}_{\text {person }}=$ 155. Subscript $0=$ person-centered. Subscript $1=$ person-mean. Bold indicates level-0 (day) correlations. Italic indicates level-1 (person) correlations. ICC $_{1}$ shows the proportion of variance accounted for at level-1.

Table 3

Results of a Multi-level Confirmatory Factor Analysis of FSSB and PSR.

\begin{tabular}{lcccc}
\hline Fit Statistic & $\begin{array}{c}\text { Null } \\
\text { Model }\end{array}$ & $\begin{array}{c}\text { Independence } \\
\text { Model }\end{array}$ & $\begin{array}{c}\text { One } \\
\text { Factor- } \\
\text { Level 1 }\end{array}$ & $\begin{array}{c}\text { Full } \\
\text { Measurement } \\
\text { Model }\end{array}$ \\
\hline$\chi^{2}(\mathrm{df})$ & $\begin{array}{c}2293.84^{*} \\
(41)\end{array}$ & $\begin{array}{c}1271.22^{*} \\
(34)\end{array}$ & $\begin{array}{c}265.14^{*} \\
(27)\end{array}$ & $\begin{array}{c}104.85^{*} \\
(26)\end{array}$ \\
RMSEA & 0.23 & 0.19 & 0.09 & 0.05 \\
$(95 \% \mathrm{CI})$ & $(.22, .24)$ & $(.18, .19)$ & $(.08, .10)$ & $(.04, .07)$ \\
CFI & 0.17 & 0.67 & 0.95 & 0.98 \\
TLI & 0.15 & 0.59 & 0.92 & 0.98 \\
$\Delta \chi^{2}(\mathrm{df})$ & & $1022.62^{*}(7)$ & 62.39 & $(13)$ \\
\hline
\end{tabular}

Notes: $* \mathrm{p}<.05 . \mathrm{N}_{\text {day }}=1054 ; \mathrm{N}_{\text {person }}=155$. 
Table 4

Standardized Factor Loadings and Error Variances for a Multilevel Confirmatory Factor Analysis Model of Family Supportive Supervisor Behaviors (FSSB) and Perceived Supervisor Responsiveness (PSR)

\begin{tabular}{|c|c|c|c|c|c|}
\hline Factor & Item/Factor & $\begin{array}{c}\text { Level-0 } \\
\text { Loading }\end{array}$ & $\begin{array}{c}\text { Level-0 } \\
\text { Error } \\
\text { Variance }\end{array}$ & $\begin{array}{c}\text { Level-1 } \\
\text { Loading }\end{array}$ & $\begin{array}{c}\text { Level-1 } \\
\text { Error } \\
\text { Variance }\end{array}$ \\
\hline
\end{tabular}

\section{FSSB}

Emotional 1. My supervisor made me support feel comfortable talking to him/her about conflicts .77

.98

between work and nonwork

$\begin{array}{ll}\text { Instrumental 2. My supervisor worked } & \end{array}$ support effectively with employees to creatively solve conflicts between work and non-

$\begin{array}{llll}.81 & .34 & 1.01 & -0.01\end{array}$

work

Role model 3. My supervisor demonstrated effective behaviors in how to juggle work and non-work issues

Creative 4. My supervisor organized work-family the work in my department management or unit to jointly benefit employees and the company

Omega

PSR

Accepted 1. To what degree did you feel accepted by your supervisor?

2. To what degree did you

Understood feel understood by your supervisor?

Cared for

3. To what degree did you feel cared for by your supervisor?

Omega 
Table 5

MLM Parameter Estimates

\begin{tabular}{lccc}
\hline & Model 1: JobSat & Model 2: JobSat & Model 3: JobSat \\
\cline { 2 - 4 } & Estimate (SE) & Estimate (SE) & Estimate (SE) \\
\hline Fixed Effects & $.161^{* *}(.04)$ & - & $.081(.05)$ \\
$\quad$ FSSB $_{0}$ & $.561^{* * *}(.08)$ & - & $-.153(.14)$ \\
FSSB $_{1}$ & - & $.231^{* * *}(.04)$ & $.193^{* * *}(.04)$ \\
PSR $_{0}$ & - & $.564^{* * *}(.06)$ & $.662^{* * *}(.11)$ \\
PSR $_{1}$ & & & \\
Random Effects & .552 & .417 & .413 \\
$\tau_{0}^{2}$ & .388 & .395 & .394 \\
$\sigma^{2}$ & .056 & .373 & $.022(\mathrm{PSR})$ \\
$\tau_{1}^{2}$ & .227 & .288 & .378 \\
${ }^{1}$ Level-1 R & & .293 \\
${ }^{2}$ Level-0 R & .176 & .024 & .027 \\
${ }^{3}$ Level-0 R & .017 & &
\end{tabular}

Notes: $\mathrm{N}_{\text {day }}=1054 ; \mathrm{N}_{\text {person }}=155$. Subscript $0=$ person-centered. Subscript $1=$ person-mean. $* * * \mathrm{p}<.001, * * \mathrm{p}<.01, * \mathrm{p}<.05$. All pseudo- $\mathrm{R}^{2}$ calculations relied on fixed-effects only models. ${ }^{1}$ Snijders and Bosker (1999) level-1 pseudo-R ${ }^{2}$; ${ }^{2}$ Snijders and Bosker (1999) level-0 pseudo-R ${ }^{2}{ }^{3} \mathrm{Xu}$ (2003) level-0 pseudo-R ${ }^{2}$. Satterthwaite standard errors were used to generate $p$ values. See results section for confidence intervals.

Table 6

Mediation Effects

\begin{tabular}{llc}
\hline & Estimate (SE) & 95\% Confidence Interval \\
\hline Level-0 & & \\
FSSB -> PSR (a path) & $.435(.049)$ & - \\
PSR -> JobSat (b path) & $.151(.045)$ & - \\
Mediation effect & .079 & $(.033, .130)$ \\
Level-1 & & - \\
FSSB -> PSR (a path) & $1.106(.055)$ & - \\
PSR -> JobSat (b path) & $.662(.103)$ & $(.504, .980)$ \\
Mediation effect & .735 &
\end{tabular}

Notes: Mediation effects and confidence intervals were calculated through quasiBayesian Monte Carlo estimation 


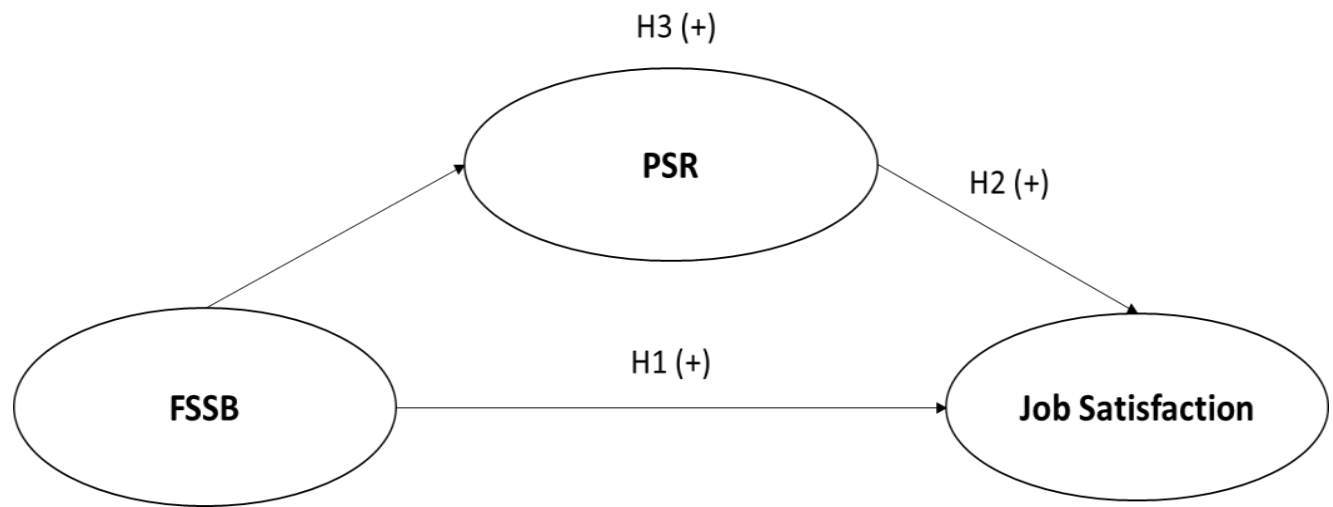

Figure 1. The hypothesized model 


\section{References}

References marked with an asterisk indicate studies involving job satisfaction as a dependent variable and FSSB as an independent variable.

Ajzen, I., \& Fishbein, M. (2005). The influence of attitudes on behavior. In D.

Albarracin, B. T. Johnson, \& M. P. Zanna (Eds.), The handbook of attitudes (pp. 173-221). Mahwah, NJ: Lawrence Erlbaum Associates Publishers.

* Allen, T. D. (2001). Family-supportive work environments: The role of organizational perceptions. Journal of Vocational Behavior, 58(3), 414-435. https://doi.org/10.1006/jvbe.2000.1774

Allen, T. D., Herst, D. E. L., Bruck, C. S., \& Sutton, M. (2000). Consequences associated with work-to-family conflict: A review and agenda for future research. Journal of Occupational Health Psychology, 5(2), 278-308. http://dx.doi.org.proxy.lib.pdx.edu/10.1037/1076-8998.5.2.278

Arpin, S. N., Starkey, A. R., Mohr, C. D., Greenhalgh, A. M. D., \& Hammer, L. B. (2018). A well spent day brings happy sleep: A dyadic study of capitalization support in military-connected couples. 32(7), 975-985.

Avolio, B. J., Sosik, J. J., Jung, D. I., \& Berson, Y. (2003). Leadership models, methods, and applications. In W. C. Borman, D. R. Ilgen, R. J. Klimoski, \& I. B. Weiner (Eds.), Handbook of Psychology. Hoboken, NJ: John Wiley \& Sons, Inc.

* Bagger, J., \& Li, A. (2014). How does supervisory family support influence employees’ attitudes and behaviors? A social exchange perspective. Journal of Management, 40(4), 1123-1150. https://doi.org/10.1177/0149206311413922 
Baruch-Feldman, C., Brondolo, E., Ben-Dayan, D., \& Schwartz, J. (2002). Sources of social support and burnout, job satisfaction, and productivity. Journal of Occupational Health Psychology, 7(1), 84-93.

http://dx.doi.org.proxy.lib.pdx.edu/10.1037/1076-8998.7.1.84

Bates, D., Mächler, M., Bolker, B., \& Walker, S. (2015). Fitting linear mixed-effects models using lme4. Journal of Statistical Software, 67(1), 1-48. https://doi.org/10.18637/jss.v067.i01

Bauer, T. N., \& Green, S. G. (1996). Development of leader-member exchange: A longitudinal test. The Academy of Management Journal, 39(6), 1538-1567. https://doi.org/10.2307/257068

* Behson, S. J. (2005). The relative contribution of formal and informal organizational work-family support. Journal of Vocational Behavior, 66(3), 487-500. https://doi.org/10.1016/j.jvb.2004.02.004

Blau, G. (1981). An empirical investigation of job stress, social support, service length, and job strain. Organizational Behavior and Human Performance, 27(2), 279302. https://doi.org/10.1016/0030-5073(81)90050-7

Blau, P. M. (1964). Exchange and power in social life. NY: John Wiley \& Sons, Inc.

Bliese, P. D., Maltarich, M. A., Hendricks, J. L., Hofmann, D. A., \& Adler, A. B. (2019). Improving the measurement of group-level constructs by optimizing betweengroup differentiation. Journal of Applied Psychology, 104(2), 293-302. https://doi.org/10.1037/ap10000349 
Bosch, M. J., Heras, M. L., Russo, M., Rofcanin, Y., \& Grau i Grau, M. (2018). How context matters: The relationship between family supportive supervisor behaviours and motivation to work moderated by gender inequality. Journal of Business Research, 82, 46-55. https://doi.org/10.1016/j.jbusres.2017.08.026

* Breaugh, J. A., \& Frye, N. K. (2007). An examination of the antecedents and consequences of the use of family-friendly benefits. Journal of Managerial Issues, 19(1), 35-52. Retrieved from JSTOR.

Breevaart, K., Bakker, A. B., Demerouti, E., \& van den Heuvel, M. (2015). Leadermember exchange, work engagement, and job performance. Journal of Managerial Psychology, 30(7), 754-770. https://doi.org/10.1108/JMP-03-20130088

Bretherton, I. (1992). The origins of attachment theory: John Bowlby and Mary Ainsworth. Developmental Psychology, 28(5), 759-775. http://dx.doi.org.proxy.lib.pdx.edu/10.1037/0012-1649.28.5.759

Brief, A. P., \& Weiss, H. M. (2002). Organizational behavior: Affect in the workplace. Annual Review of Psychology, 53(1), 279-307. https://doi.org/10.1146/annurev.psych.53.100901.135156

Caplan, R. D., Cobb, S., Harrison, R. V., \& Pinneau, S. R. Jr. (1975). Job demands and worker health: Main effects and occupational differences (No. NIOSH Publication No. 75-160). Retrieved from U.S. Department of Health, Education, and Welfare website: https://deepblue.lib.umich.edu/handle/2027.42/99318 
Carsten, J. M., \& Spector, P. E. (1987). Unemployment, job satisfaction, and employee turnover: A meta-analytic test of the muchinsky model. Journal of Applied Psychology, 72(3), 374-381.

Clark, M. S., \& Lemay, E. P. (2010). Close relationships. In S. T. Fiske, D. T. Gilbert, \& G. Lindzey (Eds.), Handbook of Social Psychology (pp. 898-940). https://doi.org/10.1002/9780470561119.socpsy001002

Clark, M. S., \& Mills, J. (1993). The difference between communal and exchange relationships: What it is and is not. Personality and Social Psychology Bulletin, 19(6), 684-691. https://doi.org/10.1177/0146167293196003

Cohen, S., \& Wills, T. A. (1985). Stress, social support, and the buffering hypothesis. Psychological Bulletin, 98(2), 310-357. http://dx.doi.org.proxy.lib.pdx.edu/10.1037/0033-2909.98.2.310

Connolly, J. J., \& Viswesvaran, C. (2000). The role of affectivity in job satisfaction: A meta-analysis. Personality and Individual Differences, 29(2), 265-281. https://doi.org/10.1016/S0191-8869(99)00192-0

Crain, T. L., \& Stevens, S. C. (2018). Family-supportive supervisor behaviors (FSSB): A review and recommendations for future research and practice. Journal of Organizational Behavior.

Cropanzano, R., \& Mitchell, M. S. (2005). Social exchange theory: An interdisciplinary review. Journal of Management, 31(6), 874-900. https://doi.org/10.1177/0149206305279602 
Cullen, J. C., \& Hammer, L. B. (2007). Developing and testing a theoretical model linking work-family conflict to employee safety. Journal of Occupational Health Psychology, 12(3), 266-278. http://dx.doi.org.proxy.lib.pdx.edu/10.1037/10768998.12.3.266

Dienesch, R. M., \& Liden, R. C. (1986). Leader-member exchange model of leadership: A critique and further development. The Academy of Management Review, 11(3), 618-634. https://doi.org/10.2307/258314

Dormann, C., \& Zapf, D. (2001). Job satisfaction: A meta-analysis of stabilities. Journal of Organizational Behavior, 22(5), 483-504. https://doi.org/10.1002/job.98

Dulebohn, J. H., Bommer, W. H., Liden, R. C., Brouer, R. L., \& Ferris, G. R. (2012). A meta-analysis of antecedents and consequences of leader-member exchange: Integrating the past with an eye toward the future. Journal of Management, 38(6), 1715-1759. https://doi.org/10.1177/0149206311415280

Dunn, T. J., Baguley, T., \& Brunsden, V. (2014). From alpha to omega: A practical solution to the pervasive problem of internal consistency estimation. British Journal of Psychology, 105(3), 399-412. https://doi.org/10.1111/bjop.12046

Eby, L. T., Casper, W. J., Lockwood, A., Bordeaux, C., \& Brinley, A. (2005). Work and family research in IO/OB: Content analysis and review of the literature (19802002). Journal of Vocational Behavior, 66(1), 124-197. https://doi.org/10.1016/j.jvb.2003.11.003

Emerson, R. M. (1976). Social Exchange Theory. Annual Review of Sociology, 2(1), 335-362. https://doi.org/10.1146/annurev.so.02.080176.002003 
Erdogan, B., \& Bauer, T. N. (2014). Leader-Member Exchange (LMX) theory: The relational approach to leadership. In D. V. Day (Ed.), The Oxford Handbook of Leadership and Organizations. Oxford, England: Oxford University Press.

Feeney, B. C. (2007). The dependency paradox in close relationships: Accepting dependence promotes independence. Journal of Personality and Social Psychology, 92(2), 268-285. http://dx.doi.org.proxy.lib.pdx.edu/10.1037/00223514.92.2.268

Fishbein, M., \& Ajzen, I. (1972). Attitudes and opinions. Annual Review of Psychology, 23(1), 487-544. https://doi.org/10.1146/annurev.ps.23.020172.002415

* Frye, N. K., \& Breaugh, J. A. (2004). Family-friendly policies, supervisor support, work-family conflict, family-work conflict, and satisfaction: a test of a conceptual model. Journal of Business and Psychology, 19(2), 197-220. Retrieved from JSTOR.

Gable, S. L., Reis, H. T., Impett, E. A., \& Asher, E. R. (2004). What do you do when things go right? The intrapersonal and interpersonal benefits of sharing positive events. Journal of Personality and Social Psychology, 87(2), 228-245. http://dx.doi.org.proxy.lib.pdx.edu/10.1037/0022-3514.87.2.228

Geldhof, G. J., Preacher, K. J., \& Zyphur, M. J. (2014). Reliability estimation in a multilevel confirmatory factor analysis framework. Psychological Methods, 19(1), 72-91. http://dx.doi.org.proxy.lib.pdx.edu/10.1037/a0032138 
Gerstner, C. R., \& Day, D. V. (1997). Meta-analytic review of leader-member exchange theory: Correlates and construct issues. Journal of Applied Psychology, 82(6), 827-844. http://dx.doi.org.proxy.lib.pdx.edu/10.1037/0021-9010.82.6.827

Gilbreath, B., \& Benson, P. G. (2004). The contribution of supervisor behaviour to employee psychological well-being. Work \& Stress, 18(3), 255-266. https://doi.org/10.1080/02678370412331317499

Graen, G. B. (1976). Role-making processes within complex organizations. In M. D. Dunnette (Ed.), Handbook of Industrial and Organizational Psychology (pp. 1201-1245). Chicago: Rand McNally.

Graen, G. B., Dansereau, F., Minami, T., \& Cashman, J. (1973). Leadership behaviors as cues to performance evaluation. The Academy of Management Journal, 16(4), 611-623. https://doi.org/10.2307/254694

Graen, G. B., Orris, J. B., \& Johnson, T. W. (1973). Role assimilation processes in a complex organization. Journal of Vocational Behavior, 3(4), 395-420. https://doi.org/10.1016/0001-8791(73)90053-5

* Hammer, L. B., Ernst Kossek, E., Bodner, T., \& Crain, T. (2013). Measurement development and validation of the Family Supportive Supervisor Behavior ShortForm (FSSB-SF). Journal of Occupational Health Psychology, 18(3), 285-296. https://doi.org/10.1037/a0032612

Hammer, L. B., Kossek, E. E., Anger, W. K., Bodner, T., \& Zimmerman, K. L. (2011). Clarifying work-family intervention processes: The roles of work-family conflict 
and family-supportive supervisor behaviors. Journal of Applied Psychology, 96(1), 134-150. https://doi.org/10.1037/a0020927

* Hammer, L. B., Kossek, E. E., Yragui, N. L., Bodner, T. E., \& Hanson, G. C. (2009). Development and validation of a multidimensional measure of family supportive supervisor behaviors (FSSB). Journal of Management, 35(4), 837-856. https://doi.org/10.1177/0149206308328510

Hammer, L. B., Kossek, E. E., Zimmerman, K. L., \& Daniels, R. (2007). Clarifying the construct of family-supportive supervisory behaviors (FSSB): A multilevel perspective. In P. L. Perrewé \& D. C. Ganster (Eds.), Research in occupational stress and well-being. UK: Emerald Group Publishing Limited.

Hammer, L. B., Wan, W. H., Brockwood, K. J., Bodner, T., \& Mohr, C. D. (2018). Supervisor support training effects on veteran health and work outcomes in the civilian workplace. Journal of Applied Psychology. https://doi.org/10.1037/apl0000354

Hammer, L. B., Wan, W. H., Brockwood, K. J., Mohr, C. D., \& Carlson, K. F. (2017). Military, Work, and Health Characteristics of Separated and Active Service Members From the Study for Employment Retention of Veterans (SERVe). Military Psychology, 29(6), 491-512. https://doi.org/10.1037/mil0000196

Hill, R. T., Matthews, R. A., \& Walsh, B. M. (2016). The emergence of family-specific support constructs: Cross-level effects of family-supportive supervision and family-supportive organization perceptions on individual outcomes. Stress and Health, 32(5), 472-484. https://doi.org/10.1002/smi.2643 
Hobfoll, S. E. (1989). Conservation of resources: A new attempt at conceptualizing stress. American Psychologist, 513-524.

Hogg, M. A. (2010). Influence and leadership. In S. T. Fiske, D. T. Gilbert, \& Lindzey (Eds.), Handbook of Social Psychology (5th ed., pp. 1156-1207). Hoboken, NJ: John Wiley \& Sons, Inc.

House, J. S., \& Wells, J. A. (1977). Occupational stress, social support, and health. Paper presented at the Conference on Reducing Occupational Stress, White Plains, New York.

Hox, J. J. (2010). Multilevel analysis (2nd ed.). New York, NY: Routledge.

Humphrey, S. E., Nahrgang, J. D., \& Morgeson, F. P. (2007). Integrating motivational, social, and contextual work design features: A meta-analytic summary and theoretical extension of the work design literature. Journal of Applied Psychology, 92(5), 1332-1356. https://doi.org/10.1037/0021-9010.92.5.1332

* Hwang, W., \& Ramadoss, K. (2017). The job demands-control-support model and job satisfaction across gender: The mediating role of work-family conflict. Journal of Family Issues, 38(1), 52-72. https://doi.org/10.1177/0192513X16647983

Ilies, R., \& Judge, T. A. (2002). Understanding the dynamic relationships among personality, mood, and job satisfaction: A field experience sampling study. Organizational Behavior and Human Decision Processes, 89(2), 1119-1139. https://doi.org/10.1016/S0749-5978(02)00018-3 
Ilies, R., Nahrgang, J. D., \& Morgeson, F. P. (2007). Leader-member exchange and citizenship behaviors: A meta-analysis. Journal of Applied Psychology, 92(1), 269-277. http://dx.doi.org.proxy.lib.pdx.edu/10.1037/0021-9010.92.1.269

Ilies, R., Wilson, K. S., \& Wagner, D. T. (2009). The spillover of daily job satisfaction onto employees' family lives: The facilitating role of work-family integration. Academy of Management Journal, 52(1), 87-102. https://doi.org/10.5465/amj.2009.36461938

Janssen, O., \& Gao, L. (2015). Supervisory responsiveness and employee self-perceived status and voice behavior. Journal of Management, 41(7), 1854-1872. https://doi.org/10.1177/0149206312471386

Janssen, O., \& Van Yperen, N. W. (2004). Employees' goal orientations, the quality of leader-member exchange, and the outcomes of job performance and job satisfaction. Academy of Management Journal, 47(3), 368-384.

Judge, T. A., \& Hulin, C. L. (1993). Job satisfaction as a reflection of disposition: A multiple source causal analysis. Organizational Behavior and Human Decision Processes, 56(3), 388-421. https://doi.org/10.1006/obhd.1993.1061

Judge, T. A., Thoresen, C. J., Bono, J. E., \& Patton, G. K. (2001). The job satisfactionjob performance relationship: A qualitative and quantitative review. Psychological Bulletin, 127(3), 376-407.

Judge, T. A., Weiss, H. M., Kammeyer-Mueller, J. D., \& Hulin, C. L. (2017). Job attitudes, job satisfaction, and job affect: A century of continuity and of change. 
Journal of Applied Psychology, 102(3), 356-374.

http://dx.doi.org.proxy.lib.pdx.edu/10.1037/ap10000181

Kahn, R. L., Wolfe, D. M., Quinn, R. P., \& Snoek, J. D. (1964). Organizational stress: Studies in role conflict and ambiguty. New York: John Wiley \& Sons, Inc.

Koch, A. R., \& Binnewies, C. (2015). Setting a good example: Supervisors as work-lifefriendly role models within the context of boundary management. Journal of Occupational Health Psychology, 20(1), 82-92. http://dx.doi.org.proxy.lib.pdx.edu/10.1037/a0037890

Kossek, E. E., \& Ozeki, C. (1998). Work-family conflict, policies, and the job-life satisfaction relationship: A review and directions for organizational behaviorhuman resources research. Journal of Applied Psychology, 83(2), 139-149. http://dx.doi.org.proxy.lib.pdx.edu/10.1037/0021-9010.83.2.139

Kossek, E. E., Petty, R. J., Bodner, T. E., Perrigino, M. B., Hammer, Leslie. B., Yragui, N. L., \& Michel, J. S. (2018). Lasting impression: Transformational leadership and family supportive supervision as resources for well-being and performance. Occupational Health Science, 1-24. https://doi.org/10.1007/s41542-018-0012-x

Kreft, I., \& DeLeeuw, J. (1998). Introducing multilevel modeling. Thousand Oaks, CA: Sage.

Lapierre, L. M., \& Hackett, R. D. (2007). Trait conscientiousness, leader-member exchange, job satisfaction and organizational citizenship behaviour: A test of an integrative model. Journal of Occupational and Organizational Psychology, 80(3), 539-554. https://doi.org/10.1348/096317906X154892 
Las Heras, M., Bosch, M. J., \& Raes, A. M. L. (2015). Sequential mediation among family friendly culture and outcomes. Journal of Business Research, 68(11), 2366-2373. https://doi.org/10.1016/j.jbusres.2015.03.042

Laurenceau, J.-P., Barrett, L. F., \& Pietromonaco, P. R. (1998). Intimacy as an interpersonal process: The importance of self-disclosure, partner disclosure, and perceived partner responsiveness in interpersonal exchanges. Journal of Personality and Social Psychology, 74(5), 1238-1251. http://dx.doi.org.proxy.lib.pdx.edu/10.1037/0022-3514.74.5.1238

Li, A., Shaffer, J., \& Bagger, J. (2015). The psychological well-being of disability caregivers: Examining the roles of family strain, family-to-work conflict, and perceived supervisor support. Journal of Occupational Health Psychology, 20(1), 40-49. https://doi.org/10.1037/a0037878

Liden, R. C., Sparrowe, R. T., \& Wayne, S. J. (1997). Leader-member exchange theory: The past and potential for the future. Research in Personnel and Human Resources Management, 15, 47-119.

Lloyd, K. J., Boer, D., Keller, J. W., \& Voelpel, S. (2015). Is my boss really listening to me? The impact of perceived supervisor listening on emotional exhaustion, turnover intention, and organizational citizenship behavior. Journal of Business Ethics, 130(3), 509-524. https://doi.org/10.1007/s10551-014-2242-4

Locke, E. A. (1969). What is job satisfaction? Organizational Behavior and Human Performance, 4(4), 309-336. https://doi.org/10.1016/0030-5073(69)90013-0 
Locke, E. A. (1976). The nature and causes of job satisfaction. In M. D. Dunnette (Ed.), Handbook of Industrial and Organizational Psychology (pp. 1297-1349). Chicago: Rand McNally.

Matthews, R. A., Mills, M. J., Trout, R. C., \& English, L. (2014). Family-supportive supervisor behaviors, work engagement, and subjective well-being: A contextually dependent mediated process. Journal of Occupational Health Psychology, 19(2), 168-181. http://dx.doi.org.proxy.lib.pdx.edu/10.1037/a0036012

Matthews, R. A., \& Toumbeva, T. H. (2015). Lagged effects of family-supportive organization perceptions and supervision in relation to generalized work-related resources. Journal of Occupational Health Psychology, 20(3), 301-313. http://dx.doi.org.proxy.lib.pdx.edu/10.1037/a0038377

McCabe, C. T., Arpin, S., \& Mohr, C. D. (2016). Perceived responsiveness, stress, and coping in the workplace. In A.-S. Antoniou \& C. L. Cooper (Eds.), Coping, Personality and the Workplace (pp. 117-129). New York, New York: Routledge.

McDonald, R. P. (1999). Test homogeneity, reliability, and generalizability. In Test theory: A unified treatment (pp. 76-120). Mahwah, New Jersey: Lawrence Erlbaum Associates, Inc.

Mills, M. J., Matthews, R. A., Henning, J. B., \& Woo, V. A. (2014). Family-supportive organizations and supervisors: How do they influence employee outcomes and for whom? The International Journal of Human Resource Management, 25(12), 1763-1785. https://doi.org/10.1080/09585192.2013.860387 
Morganson, V. J., Major, D. A., \& Litano, M. L. (2017). A multilevel examination of the relationship between leader-member exchange and work-family outcomes. Journal of Business and Psychology, 32(4), 379-393. https://doi.org/10.1007/s10869-016-9447-8

Ng, T. W. H., \& Sorensen, K. L. (2008). Toward a further understanding of the relationships between perceptions of support and work attitudes: A meta-analysis. Group \& Organization Management, 33(3), 243-268. https://doi.org/10.1177/1059601107313307

* Odle-Dusseau, H. N., Britt, T. W., \& Greene-Shortridge, T. M. (2012). Organizational work-family resources as predictors of job performance and attitudes: The process of work-family conflict and enrichment. Journal of Occupational Health Psychology, 17(1), 28-40. http://dx.doi.org.proxy.lib.pdx.edu/10.1037/a0026428

Podsakoff, P. M., MacKenzie, S. B., Lee, J.-Y., \& Podsakoff, N. P. (2003). Common method biases in behavioral research: A critical review of the literature and recommended remedies. The Journal of Applied Psychology, 88(5), 879-903. https://doi.org/10.1037/0021-9010.88.5.879

R Core Team. (2018). R: A language and environment for statistical computing. Retrieved from https://www.R-project.org/.

Raykov, T., \& Shrout, P. E. (2002). Reliability of scales with general structure: Point and interval estimation using a structural equation modeling approach. Structural Equation Modeling: A Multidisciplinary Journal, 9(2), 195-212. https://doi.org/10.1207/S15328007SEM0902_3 
Reis, H. T., Clark, M. S., \& Holmes, J. G. (2004). Perceived partner responsiveness as an organizing construct in the study of intimacy and closeness. In D. J. Mashek \& A. Aron (Eds.), Handbook of Closeness and Intimacy (pp. 201-225). Mahwah, New Jersey: Lawrence Erlbaum Associates, Inc.

Reis, H. T., Crasta, D., Rogge, R. D., Maniaci, M. R., \& Carmichael, C. L. (2017). Perceived Partner Responsiveness Scale (PPRS). In The Sourcebook of Listening Research (pp. 516-521). https://doi.org/10.1002/9781119102991.ch57

Reis, H. T., \& Gable, S. L. (2015). Responsiveness. Current Opinion in Psychology, 1, 67-71. https://doi.org/10.1016/j.copsyc.2015.01.001

Reis, H. T., \& Patrick, B. C. (1996). Attachment and intimacy: Component processes. In E. T. Higgins \& A. W. Kruglanski (Eds.), Social psychology: Handbook of basic principles (pp. 523-563). New York, NY: The Guilford Press.

Reis, H. T., \& Shaver, P. (1988). Intimacy as an interpersonal process. In S. W. Duck (Ed.), Handbook of Personal Relationships. Hoboken, NJ: John Wiley \& Sons Ltd.

Revelle, W., \& Zinbarg, R. E. (2008). Coefficients alpha, beta, omega, and the glb: Comments on sijtsma. Psychometrika, 74(1), 145. https://doi.org/10.1007/s11336008-9102-z

Ritter, K.-J., Matthews, R. A., Ford, M. T., \& Henderson, A. A. (2016). Understanding role stressors and job satisfaction over time using adaptation theory. Journal of Applied Psychology, 101(12), 1655-1669.

http://dx.doi.org.proxy.lib.pdx.edu/10.1037/ap10000152 
Rosseel, Y. (2012). lavaan: An R package for structural equation modeling. Journal of Statistical Software, 48(2), 1-36.

Schmidt, F. L., Le, H., \& Ilies, R. (2003). Beyond alpha: An empirical examination of the effects of different sources of measurement error on reliability estimates for measures of individual-differences constructs. Psychological Methods, 8(2), 206224. https://doi.org/10.1037/1082-989X.8.2.206

Scott, K. D., \& Taylor, G. S. (1985). An examination of conflicting findings on the felationship between job satisfaction and absenteeism: A meta-analysis. Academy of Management Journal, 28(3), 599-612. https://doi.org/10.2307/256116

Seashore, S. E. (1974). Job satisfaction as an indicator of the quality of employment. Social Indicators Research, 1(2), 135-168. https://doi.org/10.1007/BF00302885

Shinn, M., Wong, N. W., Simko, P. A., \& Ortiz-Torres, B. (1989). Promoting the wellbeing of working parents: Coping, social support, and flexible job schedules. American Journal of Community Psychology, 17(1), 31-55. https://doi.org/10.1007/BF00931201

Sijtsma, K. (2008). On the use, the misuse, and the very limited usefulness of cronbach's alpha. Psychometrika, 74(1), 107. https://doi.org/10.1007/s11336-008-9101-0

Smith, C. A., Organ, D. W., \& Near, J. P. (1983). Organizational citizenship behavior: Its nature and antecedents. Journal of Applied Psychology, 68(4), 653-663. http://dx.doi.org.proxy.lib.pdx.edu/10.1037/0021-9010.68.4.653 
Snijders, T. A. B., \& Bosker, R. J. (1994). Modeled variance in two-level models. Sociological Methods \& Research, 22(3), 342-363.

Snijders, T. A. B., \& Bosker, R. J. (1999). Multilevel Analysis (1st ed.). Thousand Oaks, CA: SAGE.

Sparr, J. L., \& Sonnentag, S. (2008). Fairness perceptions of supervisor feedback, LMX, and employee well-being at work. European Journal of Work and Organizational Psychology, 17(2), 198-225. https://doi.org/10.1080/13594320701743590

Sparrowe, R. T., \& Liden, R. C. (1997). Process and Structure in Leader-Member Exchange. The Academy of Management Review, 22(2), 522-552. https://doi.org/10.2307/259332

Spector, P. E. (1986). Perceived control by employees: A meta-analysis of studies concerning autonomy and participation at work. Human Relations, 39(11), 10051016. https://doi.org/10.1177/001872678603901104

Stogdill, R. (1974). Handbook of leadership. New York: Free Press.

Tabachnick, B. G., \& Fidel, L. S. (2013). Using multivariate statistics (6th ed.). Upper Saddle River, New Jersey: Pearson Education, Inc.

* Thomas, L. T., \& Ganster, D. C. (1995). Impact of family-supportive work variables on work-family conflict and strain: A control perspective. Journal of Applied Psychology, 80(1), 6-15. http://dx.doi.org.proxy.lib.pdx.edu/10.1037/00219010.80 .1 .6 
Thomas, \& Lankau, M. J. (2009). Preventing burnout: The effects of LMX and mentoring on socialization, role stress, and burnout. Human Resource Management, 48(3), 417-432. https://doi.org/10.1002/hrm.20288

* Thompson, C. A., \& Prottas, D. J. (2006). Relationships among organizational family support, job autonomy, perceived control, and employee well-being. Journal of Occupational Health Psychology, 11(1), 100-118. https://doi.org/10.1037/10768998.10.4.100

Tingley, D., Yamamoto, T., Hirose, K., Keele, L., \& Imai, K. (2014). mediation: R package for causal mediation analysis. Journal of Statistical Software, 59(5). https://doi.org/10.18637/jss.v059.i05

van Dierendonck, D., Haynes, C., Borrill, C., \& Stride, C. (2004). Leadership behavior and subordinate well-being. Journal of Occupational Health Psychology, 9(2), 165-175. http://dx.doi.org.proxy.lib.pdx.edu/10.1037/1076-8998.9.2.165

* Wang, P., Walumbwa, F. O., Wang, H., \& Aryee, S. (2013). Unraveling the relationship between family-supportive supervisor and employee performance. Group \& Organization Management, 38(2), 258-287.

Weiss, H. M., \& Cropanzano, R. (1996). Affective events theory: A theoretical discussion of the structure, causes and consequences of affective experiences at work. Research in Organizational Behavior, 18, 1-74.

Xu, R. (2003). Measuring explained variation in linear mixed effects models. Statistics in Medicine, 22(22), 3527-3541. https://doi.org/10.1002/sim.1572 
Yang, Y., \& Green, S. B. (2010). A note on structural equation modeling estimates of reliability. Structural Equation Modeling: A Multidisciplinary Journal, 17(1), 6681. https://doi.org/10.1080/10705510903438963

Zhang, Z., Zyphur, M. J., \& Preacher, K. J. (2009). Testing multilevel mediation using hierarchical linear models: Problems and solutions. Organizational Research Methods, 12(4), 695-719. https://doi.org/10.1177/1094428108327450 